Article

\title{
Versatile and Robust Method for Antibody Conjugation to Nanoparticles with High Targeting Efficiency
}

\author{
Indra Van Zundert ${ }^{1}{ }^{\oplus}$, Maria Bravo ${ }^{1}{ }^{\oplus}$, Olivier Deschaume ${ }^{2}{ }^{\oplus}$, Pierre Cybulski ${ }^{1}$, Carmen Bartic ${ }^{2}{ }^{\oplus}$, \\ Johan Hofkens ${ }^{1}$, Hiroshi Uji-i ${ }^{1,3}$, Beatrice Fortuni ${ }^{1, *}$ and Susana Rocha ${ }^{1, *}$ (i) \\ 1 Molecular Imaging and Photonics, Department of Chemistry, KU Leuven, Celestijnenlaan 200F, \\ 3001 Heverlee, Belgium; indra.vanzundert@kuleuven.be (I.V.Z.); maria.bravo@kuleuven.be (M.B.); \\ pierre.cybulski@kuleuven.be (P.C.); johan.hofkens@kuleuven.be (J.H.); hiroshi.ujii@kuleuven.be (H.U.-i.) \\ 2 Soft-Matter Physics and Biophysics, Department of Physics and Astronomy, KU Leuven, \\ Celestijnenlaan 200D, Box 2416, 3001 Heverlee, Belgium; olivier.deschaume@kuleuven.be (O.D.); \\ carmen.bartic@kuleuven.be (C.B.) \\ 3 Research Institute for Electronic Science (RIES), Hokkaido University, N20W10, Kita Ward, \\ Sapporo 001-0020, Japan \\ * Correspondence: beatrice.fortuni@kuleuven.be (B.F.); susana.rocha@kuleuven.be (S.R.)
}

check for updates

Citation: Van Zundert, I.; Bravo, M.; Deschaume, O.; Cybulski, P.; Bartic, C.; Hofkens, J.; Uji-i, H.; Fortuni, B.; Rocha, S. Versatile and Robust Method for Antibody Conjugation to Nanoparticles with High Targeting Efficiency. Pharmaceutics 2021, 13, 2153. https://doi.org/10.3390/ pharmaceutics13122153

Academic Editor: Hassan Bousbaa

Received: 28 September 2021

Accepted: 8 December 2021

Published: 14 December 2021

Publisher's Note: MDPI stays neutral with regard to jurisdictional claims in published maps and institutional affiliations.

Copyright: (c) 2021 by the authors. Licensee MDPI, Basel, Switzerland. This article is an open access article distributed under the terms and conditions of the Creative Commons Attribution (CC BY) license (https:/ / creativecommons.org/licenses/by/ $4.0 /)$.

\begin{abstract}
The application of antibodies in nanomedicine is now standard practice in research since it represents an innovative approach to deliver chemotherapy agents selectively to tumors. The variety of targets or markers that are overexpressed in different types of cancers results in a high demand for antibody conjugated-nanoparticles, which are versatile and easily customizable. Considering upscaling, the synthesis of antibody-conjugated nanoparticles should be simple and highly reproducible. Here, we developed a facile coating strategy to produce antibody-conjugated nanoparticles using 'click chemistry' and further evaluated their selectivity towards cancer cells expressing different markers. Our approach was consistently repeated for the conjugation of antibodies against CD44 and EGFR, which are prominent cancer cell markers. The functionalized particles presented excellent cell specificity towards CD44 and EGFR overexpressing cells, respectively. Our results indicated that the developed coating method is reproducible, versatile, and non-toxic, and can be used for particle functionalization with different antibodies. This grafting strategy can be applied to a wide range of nanoparticles and will contribute to the development of future targeted drug delivery systems.
\end{abstract}

Keywords: mesoporous silica nanoparticles; antibody functionalization; targeted drug delivery systems

\section{Introduction}

Despite the numerous advances in treatment options, cancer remains a leading cause of mortality worldwide. Existing methods bear limitations and complications, such as incomplete removal of the tumor and severe side effects. Therefore, a combination of treatments is often required to reach the desired results [1-3]. The urge to develop more effective therapies gave rise to intensive research in delivery of chemotherapeutics using nanoparticles. Engineered nanoparticles have been shown to serve as excellent drug nanocarriers. Among the advantages of using nanoparticles are their higher drug-loading capacity, the protection of the drugs against degradation during blood circulation, and the possibility to easily add other functionalities. As the size of particles can be tailored, nanoparticles between 20 and $200 \mathrm{~nm}$ can take advantage of the enhanced permeability and retention (EPR) effect, to passively accumulate near the tumor because of abnormal blood vessel architecture $[4,5]$. However, over the last years, increasing debate on the EPR effect has emerged, raising doubts about its reliability and applicability [6-8]. Moreover, it has been repeatedly reported that only a small percentage of nanoparticles intravenously injected in mouse models actually reaches the tumor cells [9-11]. This is caused by the obstacles or biological barriers encountered by nanoparticles, which limit their delivery 
to the tumor. These include the bloodstream, the innate immune system, the endothelial wall, and the dense extracellular matrix (ECM) of the tumor [12,13]. The ECM consists of fibers (such as collagen and fibronectin), which are known to hamper the diffusion of nanoparticles significantly [14]. This, together with an increased interstitial fluid pressure at the tumor site, poses a substantial barrier for nanoparticle transport to the tumor. To this end, strategies that can enhance the delivery of nanoparticles are widely being explored today. Active targeting of nanoparticles to cancer cells is one of those strategies $[15,16]$.

Over the years, a wide range of nanoparticles have been engineered and several approaches have been developed to promote nanoparticle internalization into specific cells. Often, nanoparticles are functionalized with ligands that recognize overexpressed receptors or markers present on the cancer cell membrane $[5,17,18]$. In doing so, they facilitate specific accumulation of the drug in cancer cells [19]. Folic acid or transferrinconjugated nanoparticles are popular examples of such drug delivery systems (DDSs), as they bind to folate and transferrin receptors, respectively, overexpressed in certain cancers $[18,20,21]$. Typically, one nanoparticle is designed against a particular receptor or marker, hence targeting a specific cancer. However, patients with the same type of cancer can overexpress different markers. For instance, overexpression of the estrogen receptor (ER) is linked to a hormone-sensitive form of breast cancer (ER+), while HER2 is overexpressed in an aggressive and fast-growing type of breast cancer (HER2+) [22-24]. Given the variety in potential targets, there is a continuous search for simple methods to customize nanoparticles, turning them into versatile nano-carriers. To this end, antibodies have proven to be a promising strategy as they can be developed against most of the existing markers. The success of antibodies in targeting tumor cells has already been proven with the development of antibody-drug conjugates, which have emerged as powerful therapeutic agents in cancer therapies. To date, nine ADCs have been approved by the FDA for clinical use [25-29]. After the advances in antibody-drug conjugates, conjugation of antibodies to nanoparticles yields great therapeutic potential $[30,31]$.

Conjugation of antibodies to nanoparticles can be achieved via different strategies, i.e., ionic adsorption (non-covalent attachment) [32], covalent binding (including carbodiimide chemistry [33], maleimide chemistry [34] and click-chemistry [35]) or using adapter molecules such as biotin [36]. In ionic adsorption, antibodies are linked to the nanoparticles via electrostatic interactions [37], leading to poor reproducibility and low stability [38]. Alternatively, adapter molecules, such as the avidin-biotin couple, can be implemented, but this interaction is influenced by the $\mathrm{pH}$, affecting nanoparticle stability in more acidic conditions as found in the tumor microenvironment [39].

Covalent attachment is achieved by functionalizing the nanoparticle surface with functional groups (e.g., amine, carboxylic, maleimide etc.), which can react with the amino acid side chain of the antibody by standard conjugation methods. Covalent attachment of antibodies is generally preferred, provided that an appropriate approach is used. For instance, while EDC/NHS coupling is a common method for covalent attachment [40], it can result in oligomerization of antibody molecules [41]. Furthermore, some conjugation methods require the use of catalysts, often metals, that can lead to increased toxicity of the nanoparticles if not fully removed from the solution [42,43]. Therefore, when using covalent conjugation, a catalyst-free approach and vast optimization are important. Despite the progress in nanoparticle functionalization, there is still an urge for simple and reproducible strategies to conjugate antibodies to nanoparticles, enabling the development of versatile DDSs, which can easily be customized for selectivity towards different cancer markers.

In this work, we propose a simple and reproducible coating strategy for antibody conjugation to nanoparticles. To avoid the use of catalysts, we developed an approach based on copper-free click chemistry (Figure 1). Briefly, antibodies were labelled with a dibenzocyclooctyne $(\mathrm{DBCO})$ moiety, while an Azide $\left(\mathrm{N}_{3}\right)$ group was attached to the nanoparticles. The independent activation of the antibody and nanoparticles reduces the possibility of oligomerization of the antibody or aggregation of the particles. We proved the versatile nature of our method by creating two different types of particles, 
either conjugated to an anti-Cluster of Differentiation 44 (anti-CD44) or anti-Epidermal Growth Factor Receptor (anti-EGFR) antibody, targeting CD44 or EGFR overexpressing cells, respectively. CD44 and EGFR are surface receptors that manifest themselves as important bio-markers in cancer [44,45]. In this report, mesoporous silica nanoparticles (MSNPs) were used as a model application for our coating strategy. In recent years, MSNPs have been pointed out as extremely promising tools in cancer research given their high biocompatibility, chemical stability, high drug-loading and -releasing capacities, straightforward functionalization and low-cost, scalable fabrication [46-48]. For these reasons, MSNPs were chosen as a study model of DDSs for further surface modifications. Nevertheless, we foresee that the coating strategy here presented can be easily applied to a wide range of nano-carriers besides MSNPs, as it only requires the presence of amine groups on the surface of the nanoparticle. This simple conjugation strategy will contribute to the up-scaling of antibody-conjugated nanoparticles and to the future developments of targeted nanoparticles with multiple functionalizations.

(a) Nanoparticle - azide coupling

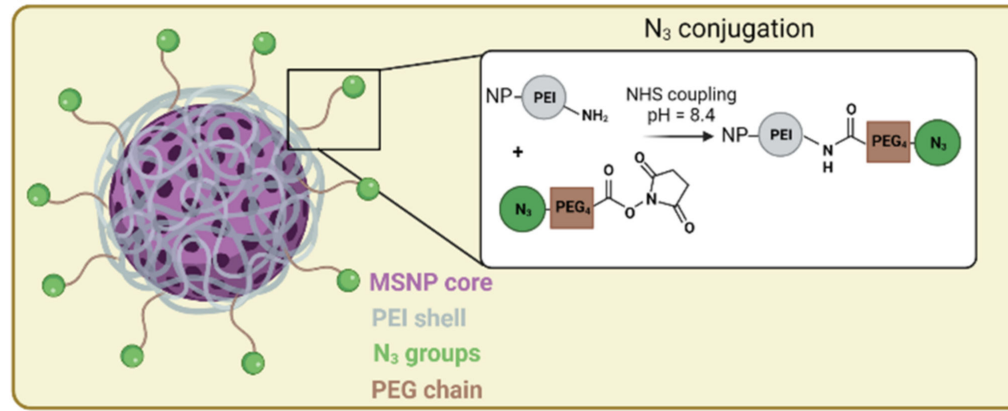

(b) Antibody labeling

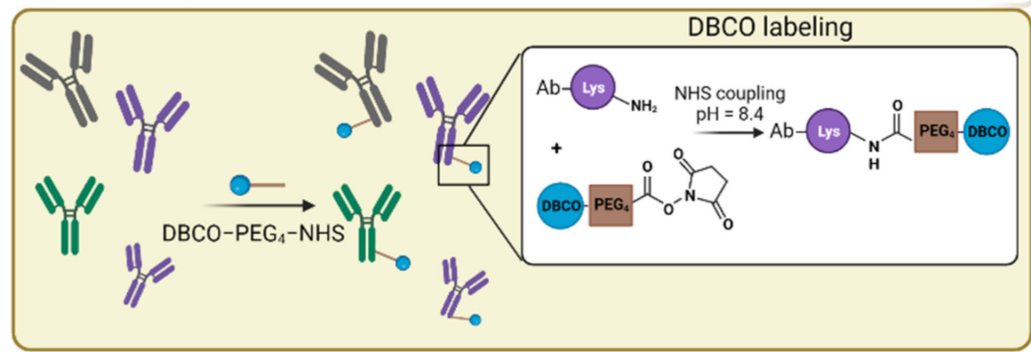

(c) Nanoparticle - Antibody conjugation

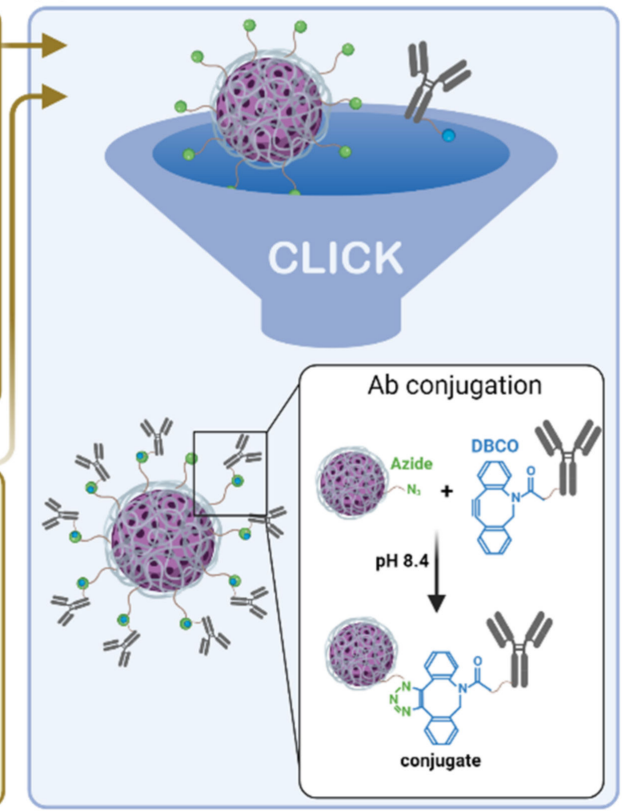

Figure 1. Schematic representation of the antibody-conjugated nanoparticle preparation: (a) Mesoporous silica nanoparticles (MSNPs) loaded with the drug (Doxorubicin) and coated with a polyethyleneimine (PEI) layer (gray) are grafted with an Azide moiety ( $\mathrm{N}_{3}$, green) using NHS ester coupling. (b) The lysine residues (purple) of different antibodies were labelled with a DBCO moiety (blue) via NHS ester coupling. (c) Click chemistry reaction of the Azide-functionalized nanoparticle with the DBCO-labelled antibodies resulting in the final antibody-conjugated nanoparticle.

\section{Materials and Methods}

\subsection{Materials}

Mouse anti-human EGFR ( $\alpha$ EGFR, monoclonal, cat. BE0278) and rat anti-human CD44 ( $\alpha$ CD44, monoclonal, hermes-1, cat. BE0039) were purchased from Bio X Cell (Lebanon, NH, USA). Goat anti-rabbit IgG (cat. ab6702) was purchased from Abcam (Cambridge, United Kingdom). Secondary antibodies, donkey anti-rat IgG Alexa Fluor 488 (cat. A-21208)goat anti-mouse IgG Alexa Fluor 488 (cat. A11001), Dulbecco's modified eagle medium (DMEM), LysoTracker $^{\mathrm{TM}}$ Deep Red, DiR lipophilic dye, Gentamicin, Dulbecco's phosphate buffered saline (PBS, no calcium, no magnesium), Formaldehyde (4\% in PBS), trypsin-EDTA (0.5\%), Hank's balanced salt solution (HBSS, no phenol red), Ethanol (absolute, 99.9\%), donkeyanti-rat IgG-Alexa Fluor 488 (cat. A-21208), and Zeba ${ }^{\text {TM }}$ Spin Desalting Columns (40K MWCO, $0.5 \mathrm{~mL}$ ) were purchased from ThermoFisher Scientific (Waltham, MA, USA). 
Tetraethyl orthosilicate (TEOS, 98\%), cetyltrimethylammonium chloride solution (CTAC, $25 \%$ in $\mathrm{H}_{2} \mathrm{O}$ ), triethanolamine (TEA, $99 \%$ ), hydrochloric acid $(\mathrm{HCl}, 1 \mathrm{~N}$ ), Rhodamine $\mathrm{B}$ basic violet 10 (RhoB, 93\%), Fluorescein isothiocyanate (FITC), (3-Aminopropyl)triethoxysilane (APTES), polyethyleneimine solution (PEI, $50 \% w / v$ in $\mathrm{H}_{2} \mathrm{O}$ ), Triton X-100 $(0.1 \%), \mathrm{N}-(3-$ dimethylaminopropyl)- $N^{\prime}$-ethyl-carbodiimide (EDC, 97\%), Dimethyl sulfoxide (DMSO, $>99.5 \%$ ) and 3D Petri Dish ${ }^{\circledR}$-Microtissues were purchased from Sigma Aldrich (Saint Louis, MO, USA). Atto488 and Atto565 NHS ester conjugate were purchased from Atto-TEC $\mathrm{GmbH}$ (Martinshardt, Siegen, Germany). DBCO-PEG4-NHS-ester and $\mathrm{N}_{3}-\mathrm{PEG}_{4}$-NHS-ester were purchased from Click Chemistry Tools (Scottsdale, AZ, USA). The A549 cell line was obtained from Sigma Aldrich (ECACC 86012804). The A431, Hek293T and NIH3T3 cell lines were a kind gift from Prof. Hideaki Mizuno (KU Leuven, Belgium) [49,50]. The HepG2 cell line was obtained from Prof. Hitoshi Kasai (Institute of Multidisciplinary Research for Advanced Materials (IMRAM, Chome-1-1 Katahira, Aoba Ward, Sendai, Miyagi 980-8577, Japan [51]). BJ1-hTERT cells were a kind gift of Dr. Barderas (Instituto Salud D. Carlos III, Spain). FuGENE ${ }^{\circledR} 6$ and Alexa Fluor 488 HaloTag ${ }^{\circledR}$ ligand were both purchased from Promega (Madison, WI, USA). The pcDNA3-EGFR-HaloTag ${ }^{\circledR}$ plasmid was a kind gift from the laboratory of Prof. Dr. Hideaki Mizuno (KU Leuven, Belgium). All the chemicals were used without further purifications.

\subsection{CD44, EGFR and IgG Antibody Labelling}

The antibodies (rat anti-human CD44, mouse anti-human EGFR and goat anti-rabbit $\operatorname{IgG}$ ) were functionalized with $\mathrm{DBCO}-\mathrm{PEG}_{4}-\mathrm{NHS}$ ester for conjugation onto the nanoparticles via copper-free click chemistry. In addition, a fluorescent label, Atto565-NHS ester (for the EGFR antibody and the IgG) or Atto488-NHS ester (for the CD44 antibody), was sometimes grafted onto the antibody for further investigations via fluorescence microscopy. The labelling of $500 \mu \mathrm{g}$ of antibody was carried out in $50 \mathrm{mM}$ of borate buffer $\mathrm{pH} 8.5$ (antibody concentration $1 \mathrm{mg} / \mathrm{mL}$ ). Then, 10 molar equivalents of DBCO-PEG 4 -NHS ester and 2 molar equivalents of Atto565-NHS ester or Atto488-NHS ester (when needed) were added to the reaction, according to Eggermont and Hammink et al. [52]. After $6 \mathrm{~h}$ under magnetic stirring at room temperature, the dual labelled antibodies were purified over a $0.5-\mathrm{mL} 40 \mathrm{~K}$ Zeba desalting column to remove residual-free Atto565-NHS ester and DBCO-PEG 4 -NHS ester molecules. After purification, absorption measurements were carried out using a UV-VIS spectrophotometer (BioDrop $\mu$ Lite, BioChrom in Figure S2). The absorption at different wavelengths was used to determine the concentration of protein, $\mathrm{DBCO}$ and fluorescence dyes $\left(\mathrm{A}_{280}\right.$ for the antibody, $\mathrm{A}_{309}$ for DBCO, $\mathrm{A}_{488}$ for Atto488 and $A_{565}$ for Atto565). The values obtained corresponded to a labelling degree of an average of 10 molecules of DBCO and 2 dye molecules per antibody (absorption spectra shown in Figure S2). Previous reports have shown that this degree of labelling does not induce loss of antibody specificity [53].

\subsection{Synthesis MSNPs}

The MSNPs were synthetized by the biphase stratification method reported by Shen et al. [54]. In short, $0.18 \mathrm{~g}$ of TEA was mixed with a solution of $24 \mathrm{~mL}$ of CTAC and $36 \mathrm{~mL}$ of milli-Q water. This mixture was heated to $60^{\circ} \mathrm{C}$ under magnetic stirring for $1 \mathrm{~h}$. Next, $20 \mathrm{~mL}$ of TEOS ( $20 \mathrm{v} / \mathrm{v}$ in octadecene) was slowly added with a syringe and the reaction was kept proceeding overnight. When fluorescein (FITC) was linked to the MSNPs' matrix (FITC encapsulation), $16.6 \mathrm{mg}$ of FITC was dissolved in $10 \mathrm{~mL} 99.8 \%$ ethanol and $400 \mu \mathrm{L}$ of (3-Aminopropyl)triethoxysilane (APTES). This mixture was stirred for $2 \mathrm{~h}$ under inert atmosphere to couple FITC to the aminosilane. After $2 \mathrm{~h}$, the solution was added together with the TEOS. Next, the reaction was cooled down to room temperature and the nanoparticles were washed with a solution of $\mathrm{HCl} 1.1 \mathrm{M}$ in water/ethanol $(v / v=1.25: 10)$ with centrifugation-dispersion-sonication cycles to remove CTAC from the pores.

Subsequently, the nanoparticles were washed two times with milli- $\mathrm{Q}$ water in order to neutralize the $\mathrm{pH}$. 


\subsection{MSNP Dye/Drug Loading}

The pores of the MSNPs were loaded with doxorubicin (Dox) or rhodamine B (RhoB) for cytotoxicity experiments and fluorescence imaging, respectively. Loading of RhoB was performed in milli-Q water under magnetic stirring for $3 \mathrm{~h}$. For Dox loading, MSNPs were first dispersed in phosphate buffer ( $\mathrm{pH} 9$ ) to maximize the loading efficiency. To avoid Dox aggregation, the solution containing Dox and MSNPs was sonicated for $10 \mathrm{~min}$. Next, the solution was stirred for $24 \mathrm{~h}$ at $400 \mathrm{rpm}$. After loading (of Dox or RhoB), the solution was centrifuged and the supernatant was replaced with milli-Q water and the Dox- and RhoB-loaded nanoparticles were re-suspended (MSNPs_Dox and MSNPs_RhoB, respectively). The supernatants of all the centrifugation steps were collected and measured with a spectrometer in order to quantify the Dox loaded inside the MSNPs. We estimated a Dox concentration in the MSNPs of approximately $50 \mu \mathrm{M}$.

\subsection{MSNP Functionalization}

To coat the nanoparticles with a PEI layer, a $0.75 \%$ PEI solution (in milli-Q water), adjusted to $\mathrm{pH} 7$ (with $37 \% \mathrm{HCl}$ ) was added to the dye or drug-loaded MSNPs (1:1 ratio) in a plastic vial. This mixture was magnetically stirred for $3 \mathrm{~h}$, yielding PEI-coated MSNPs. To facilitate the Azide conjugation, PEI-coated particles were dispersed in borate buffer ( $\mathrm{pH}$ 8.5). To conjugate the NHS ester- $\mathrm{PEG}_{4}-\mathrm{N}_{3}$ linker to the PEI amine groups, an NHS ester reaction was used. In detail, $1.5 \mathrm{mg}$ NHS ester-PEG $\mathrm{P}_{4} \mathrm{~N}_{3}$ (in DMSO) were added to $500 \mu \mathrm{L}$ of PEI-MSNPs $(10 \mathrm{mg} / \mathrm{mL})$ in a dropwise manner and magnetically stirred for $4 \mathrm{~h}$. After the reaction, the nanoparticles were centrifuged and re-dispersed in borate buffer ( $\mathrm{N}_{3}$-PEI-MSNPs). To conjugate the desired antibody via a copper-free click reaction, $100 \mu \mathrm{g}$ of labelled antibody ( $50 \mu \mathrm{L}$ of $1 \mathrm{mg} / \mathrm{mL}$ labelled antibody solution in borate buffer) were added to $450 \mu \mathrm{L}$ of $\mathrm{N}_{3}$-PEI-MSNPs $(10 \mathrm{mg} / \mathrm{mL})$. The reaction was stirred for $6 \mathrm{~h}$ at room temperature. After the reaction, nanoparticles (Ab-PEI-MSNPs) were centrifuged at low speed (700 RPM) and re-dispersed in milli-Q water.

\subsection{Ab-PEI-MSNPs' Characterization}

The synthesized nanoparticles were characterized by confocal fluorescence microscopy, scanning electron microscopy (SEM,) and atomic force microscopy (AFM). For the fluorescence microscopy experiments, $60 \mu \mathrm{L}$ Ab-PEI-MNSP solution was pipetted in a Coverwell ${ }^{\mathrm{TM}}$ perfusion chamber (ThermoFisher Scientific) placed onto a \#1 coverglass. After $30 \mathrm{~min}$, when some nanoparticles had sedimented, the sample was imaged with a Leica TCS SP8 mini microscope (Wetzlar, Germany). For SEM measurements, nanoparticles were dropcasted onto an Indium-Tin Oxide-coated glass and dried. Next, the glass was coated with $\mathrm{Au} / \mathrm{Pd}$ for $20 \mathrm{~s}$. Nanoparticles were visualized using a FEI Quanta 250 FEG Scanning Electron Microscope (ThermoFisher Scientific). Zeta potential measurements were carried out on a Malvern Zetasizer system (Malvern, UK). For AFM characterization, an Agilent 5500 AFM with MAC III controller was used for morphological imaging in intermittent contact mode in air. MSNL-F $\left(\mathrm{f}=120 \mathrm{kHz}, \mathrm{k}=0.6 \mathrm{~N} \mathrm{~m}^{-1}\right.$, tip radius of curvature $<12$ $\mathrm{nm}$ ) probes were used. The AFM topography images were leveled, line-corrected, and measured (line profiles for diameter determination) using Gwyddion, a free and opensource SPM (scanning probe microscopy) data visualization and analysis program (version 2.48) [55]. AFM samples were prepared on silicon substrates freshly cleaned in piranha solution. For bare and functionalized MSNPs that carry a negative surface charge, the clean substrate was first incubated in $\mathrm{PAH}$, followed by rinsing and drying. On the other hand, PEI-modified MSNPs were deposited on a bare silicon substrate. For each sample, the nanoparticle suspension was incubated for $1 \mathrm{~min}$ on the substrate, before rinsing with ultrapure water and drying with pure nitrogen gas. To check the colloidal stability of the Ab-PEI-MSNPs, turbidity measurements were performed. Accordingly, the sample turbidity (optical density) of the nanoparticles dissolved in different media (milli- $\mathrm{Q}$ water, FBS and DMEM+10\% FBS) was determined before and after $24 \mathrm{~h}$ of incubation at $37^{\circ} \mathrm{C}$ by measuring the absorbance at $600 \mathrm{~nm}$. 


\subsection{Cell Culture}

A549 cells, HepG2, BJ1-hTERT, NIH3T3, Hek293 and A431 cells were cultured in $25 \mathrm{~cm}^{2}$ culture flasks at $37^{\circ} \mathrm{C}$ under $5 \% \mathrm{CO}_{2}$ atmosphere. All cell lines were maintained in DMEM medium with $10 \%$ FBS, $1 \%$ L-glutamax and $0.1 \%$ gentamicin. For fluorescence microscopy experiments, the cells were seeded in 29-mm, glass-bottom dishes (Cellvis, Mountain View, CA, USA) and grown until $60 \%$ confluency before adding the nanoparticles.

\subsection{Immunofluorescence Labeling}

A549 and HepG2 cells were stained with both the dual-labelled (with DBCO and Atto488) and non-labelled CD44 antibody (rat anti-human CD44). First, cells were seeded in two glass-bottom dishes and grown overnight. Next, the cells were fixed with paraformaldehyde $(4 \%)$ and the membrane was permeabilized with Triton X-100 (0.1\%), for $10 \mathrm{~min}$. The sample was carefully washed with PBS $(1 \times)$ between each step. After washing, blocking was performed for $1 \mathrm{~h}$ with a bovine serum albumin solution (3\% in PBS). The duallabelled and non-labelled CD44 antibodies were added to the cells at a final concentration of $2 \mu \mathrm{g} / \mathrm{mL}$ and incubated overnight at $4{ }^{\circ} \mathrm{C}$. After antibody incubation, the dual-labelled antibody samples were washed three times with PBS. The samples containing non-labelled antibody were washed three times with PBS and incubated with the secondary antibody, donkey-anti-rat IgG-AF488, at a final concentration of $1 \mu \mathrm{g} / \mathrm{mL}$ for $2 \mathrm{~h}$. After that, the samples were washed with PBS. The same protocol was used for the immunofluorescent staining of A431 and Hek293 cells with both the dual-labelled and non-labelled EGFR antibody (mouse anti-human EGFR). In this case, a goat-anti-mouse IgG AF488 secondary antibody was used after incubation with the non-labelled antibody.

\subsection{Ab-PEI-MSNPs' Targeting Efficiency}

A549 cells, HepG2, BJ1-hTERT, NIH3T3, Hek293 and A431 cells were seeded in a $29 \mathrm{~mm}$, glass-bottom dish and grown until $60-80 \%$ confluency. FITC-encapsulated nanoparticles with different functionalization (bare MSNP, PEI-coated MSNPs, EGFR or CD44 antibody-conjugated MSNPs, and IgG-conjugated MSNPs) were added to the cells to a final concentration of $50 \mu \mathrm{g} / \mathrm{mL}$. After $6 \mathrm{~h}$ of incubation with the NPs, the cells were washed three times with PBS and fresh medium was added to the samples. The samples were placed back in the incubator for an additional $24 \mathrm{~h}$ incubation. Prior to imaging, the plasma membrane was stained using DiR $(1 \mu \mathrm{M})$ in HBSS for 13 min and the sample was washed three times with HBSS. The resulting images were analyzed to quantify the amount of nanoparticle internalization by calculating the mean fluorescence intensity of the nanoparticle signal inside at least 20 cells per condition using the Fiji open source software (version 1.51). [56]. Briefly, the cell area (region of interest, ROI) was manually selected based on the membrane staining. Next, the mean fluorescence intensity of the nanoparticles was calculated for each ROI.

\subsection{Transfection of Hek 293}

Hek293 was reverse transfected with a pcDNA3-EGFR-HaloTag ${ }^{\circledR}$ [50]. Transfection was carried out according to the supplier's protocol (FuGENE ${ }^{\circledR}$ 6, Promega). Briefly, $1 \mu \mathrm{g}$ of DNA was added to $100 \mu \mathrm{L}$ of serum-free DMEM medium together with $3 \mu \mathrm{L}$ of the transfection reagent. This mixture was vortexed shortly and incubated for $17 \mathrm{~min}$. Meanwhile, the cells were passaged and plated in 29-mm, glass-bottom dishes (Cellvis). After $17 \mathrm{~min}$ of incubation, the transfection mixture was added to the plated cells in a dropwise manner. The next day, $\alpha$ EGFR-PEI-MSNPs were added to the transfected Hek293 cells. After $3 \mathrm{~h}$, the medium was refreshed to avoid continued uptake of nanoparticles. The cells were incubated with the nanoparticles for a total of $24 \mathrm{~h}$. After incubation, EGF receptor was visualized in the transfected Hek293 cells after incubation with the Alexa Fluor 488 HaloTag ${ }^{\circledR}$ ligand (Promega) for $30 \mathrm{~min}$ at $37^{\circ} \mathrm{C}$ (final ligand concentration of $250 \mathrm{nM}$ in cell medium). 


\subsection{Fluorescence Microscopy}

Confocal fluorescence imaging was performed on a Leica TCS SP8 mini microscope implementing a HC PL APO 63× water immersion objective (NA 1.2). Distinct diode lasers were used depending on the dye. For LysoTracker ${ }^{\mathrm{TM}}$ DeepRed and DiR lipophilic dye, a red, 638-nm diode laser was used at a laser power between 10 and $60 \mu \mathrm{W}$. For RhoB or Atto565 detection, a green, 552-nm diode laser was used for excitation (laser power between 20 and $80 \mu \mathrm{W}$ ), while the blue, 488 -nm diode laser was used to excite Doxorubicin, FITC and Atto488 (laser power between 10 and $50 \mu \mathrm{W}$ ). The laser powers were measured at the objective. Detection was performed with HyD SMD high-sensitivity detectors in standard mode, operating in a detection range of 400 to $800 \mathrm{~nm}$. The detection range was adjusted depending on the dye, with 500-550 nm for Atto488 and FITC detection, 570$600 \mathrm{~nm}$ for Doxorubicin, RhoB, and Atto565 and 650-750 nm for LysoTracker ${ }^{\mathrm{TM}}$ DeepRed and DiR lipophilic dye detection. The images were acquired with a z-step of $1 \mu \mathrm{m}$ and line averaging of 3 .

\subsection{The $\alpha C D 44-P E I-M S N P s^{\prime}$ Intracellular Localization}

A549 cells were incubated with $\alpha$ CD44-PEI-MSNPs_RhoB for $24 \mathrm{~h}$ (at a final concentration of $50 \mu \mathrm{g} / \mathrm{mL}$ ). The sample was then washed three times with PBS to remove extracellular nanoparticles and kept in HBSS during image acquisition. One sample was imaged immediately after 24-h incubation, while two other replicates were placed back in the incubator for the 48-and 72-h time points (after replacing the PBS for cell culture medium). Prior to imaging, the samples were washed with HBSS and the lysosomes were stained with LysoTracker ${ }^{\mathrm{TM}}$ Deep Red (100 $\mathrm{nM}$ final concentration in HBSS) for $15 \mathrm{~min}$. After washing three times with PBS, the samples were imaged in HBSS. The fluorescence images acquired (see Fluorescence microscopy section) were processed and analyzed using Fiji and the built-in, co-localization plugin JACoP [57]. Within this plugin, Manders co-localization was found as an appropriate analysis strategy as this method measures the fraction of co-occurrence of the signal in two channels rather than their correlation [58]. After manual selection of the cell area with the region of interest (ROI) manager, the Manders' coefficient (MC) was calculated for 28-40 biological replicates for each time point (using three technical replicates). More specifically, MC indicates the fraction of pixels of the $\alpha$ CD44-PEI-MSNPs' ROI that overlap with the pixels of the LysoTracker ROI, resulting in a value between 0 and 1 . One means that $100 \%$ of the pixels of the $\alpha$ CD44-PEI-MSNP ROI overlap with the pixels of the LysoTracker channel, with 0 being a $0 \%$ pixel overlap.

\subsection{Doxorubicin Release}

The $\alpha$ CD44-PEI-MSNPs were loaded with doxorubicin to a final concentration of $40 \mu \mathrm{M}$ ( $\alpha$ CD44-PEI-MSNP_Dox). A549 cells were incubated with $\alpha$ CD44-PEI-MSNP_Dox for $24 \mathrm{~h}$. After $24 \mathrm{~h}$ of incubation, the sample was washed with PBS three times to remove extracellular nanoparticles and kept in HBSS during image acquisition. One sample was immediately measured (with confocal fluorescence microscopy), while two other replicates were placed back in the incubator for the 48- and 72-h time points (after replacing the PBS by cell culture medium). An additional sample was checked after $8 \mathrm{~h}$ of nanoparticle incubation, in order to monitor nanoparticle endocytosis. Prior to imaging, the samples were washed three times with PBS and the acidic vesicles were visualized by adding a solution containing LysoTracker ${ }^{\mathrm{TM}}$ Deep Red (100-nM final concentration in HBSS) for 15 min. After a final washing step with PBS, the samples were imaged in HBSS using a confocal microscope.

\subsection{Cytotoxicity Studies}

A549 and HepG2 cells were seeded in a 96-well plate at a density of $2 \times 10^{4}$ cells/well. The next day, 25, 50, 100 and $200 \mathrm{nM}$ of Dox and 25, 50, 100 and $200 \mu \mathrm{g} / \mathrm{mL}$ of empty and Dox-loaded $\alpha$ CD44-PEI-MNSPs were added to the A549 cells. Four biological replicates were prepared for each condition. Cells incubated with nanoparticles were washed with 
PBS after $24 \mathrm{~h}$ of nanoparticle incubation to remove the excess of nanoparticles. The PBS was then replaced by fresh medium and the sample was placed in the cell incubator. Then, $72 \mathrm{~h}$ after the addition of free Dox or nanoparticles, the cells were washed $3 \times$ with PBS and fixed with $4 \%$ PFA (in PBS). Cells were incubated with Hoechst $33342(1 \mu \mathrm{g} / \mathrm{mL})$ for $1 \mathrm{~h}$. After washing with PBS, the viable cells were imaged using a Lionheart FX automated microscope (BioTek, Santa Clara, CA, USA) implementing a 10 $\times$ air objective (NA: 0.3) and a high-power LED of $365 \mathrm{~nm}$, combined with a DAPI filter cube. Images were analyzed using the Gen $5^{\mathrm{TM}}$ software (version 3.11.19).

\subsection{Statistical Analysis}

The data are displayed as means \pm standard deviations and error bars indicate \pm standard deviation. A randomization test was used to compare any two groups of values and performed in the online software tool "Plots of Difference" [59]. Statistical significance was reported as ${ }^{*} p<0.05,{ }^{* *} p<0.01$, and ${ }^{* * *} p<0.001$.

\section{Results and Discussion}

\subsection{The $\alpha C D 44-C o n j u g a t e d ~ N a n o p a r t i c l e s$}

CD44 is a transmembrane glycoprotein receptor overexpressed in different cancers (e.g., breast, lung, colon, head and neck, and pancreatic cancer [60-63]) and cancer stem cells $[64,65]$. Its presence is often associated with high malignancy and chemo-resistance, making it an important cancer biomarker and target for cancer therapy. Hyaluronic acid (HA) is a ligand for the CD44 receptor and has, therefore, been widely exploited as a poly-mer coating in targeted DDSs $[2,66,67]$. The ligand, HA, is naturally present in the extracellular matrix (ECM), leading to possible competition between HA from the ECM and the HA on the nanoparticles. As an alternative, antibodies with a high affinity for CD44 can be implemented in the DDS to target the receptor [68-70].

\subsubsection{Synthesis of Azide-Functionalized MSNPs}

Our approach to conjugate antibodies to nanoparticles comprised the grafting of different groups on both the antibody and the nanoparticle, separately (Figure 1). As a model for nano-carriers, we used MSNPs. PEI-coated MSNPs were prepared as previously described [49]. Briefly, MSNPs were synthesized using the biphase stratification method and loaded with either Dox or RhoB, for cytotoxicity studies or imaging assays, respectively. The fluorescence spectra of the dye/drug-loaded MSNPs are shown in Figure S1 (Supplementary Materials). A PEI layer $(\mathrm{Mw}=1.3 \mathrm{kDa})$ was deposited on the MSNPs (PEI-MSNPs), through electrostatic interactions. In our approach, the PEI layer served two purposes: to provide the nanoparticles with the capability of endosomal escape (as reported by Fortuni et al. [49]) and to functionalize the surface of the NPs with amine groups. These amine groups were used as an anchor for further covalent functionalization. An Azide moiety was covalently linked to the PEI-MSNPs, making use of an NHS ester-PEG $\mathrm{P}_{4}-\mathrm{N}_{3}$ linker via NHS ester coupling ( $\mathrm{N}_{3}$-PEI-MSNPs, Figure $\left.1 \mathrm{a}\right)$. The central poly(ethylene)glycol (PEG) chain provided extra stealth to the DDS, increasing its biocompatibility. The resulting surface Azide groups served as docking sites for the antibodies.

\subsubsection{Labelling of CD44 Antibodies}

To attach the antibody molecules to the Azide-grafted nanoparticles, the antibodies were functionalized with a DBCO moiety (Figure 1b). Additionally, for visualization purposes, a fluorescent dye (Atto488 or Atto565) was also added, yielding dual-labelled antibodies. As described in the Methods section, labelling of the lysine residues of the antibody was achieved via an NHS ester coupling reaction. The presence of the DBCO moiety was verified via UV-VIS absorption measurements (absorption peak at $309 \mathrm{~nm}$, see Figure S2 in Supplementary Materials). To confirm that the addition of DBCO and/or fluorescent dye did not affect the specificity of the antibody, we performed immunostainings of two cell lines, A549 and HepG2 cells, with high and low expression level of CD44, 
respectively [60]. Before testing the specificity of the DBCO/Atto488-labelled antibodies, the CD44 expression level in both cell lines was evaluated using immunofluorescence. For this, we stained the cells with an unmodified CD44 antibody, followed by a second staining step with a fluorescently labelled secondary antibody. As shown in Figure 2a, CD44 receptor molecules were detected in A549 cells (localized to the cell membrane), while no CD44 immunostaining was visible on the fluorescence images acquired for HepG2 cells. A549 cells stained with the DBCO/Atto488 dual-labelled CD44 antibodies displayed a fluorescence signal on the plasma membrane, indicating that the specificity of the antibody was retained after labelling (Figure $2 \mathrm{~b}$ ). The fluorescence signal present in the nucleus was attributed to the free dye molecules still present in solution after the labelling procedure (Figure 2c).

(a)
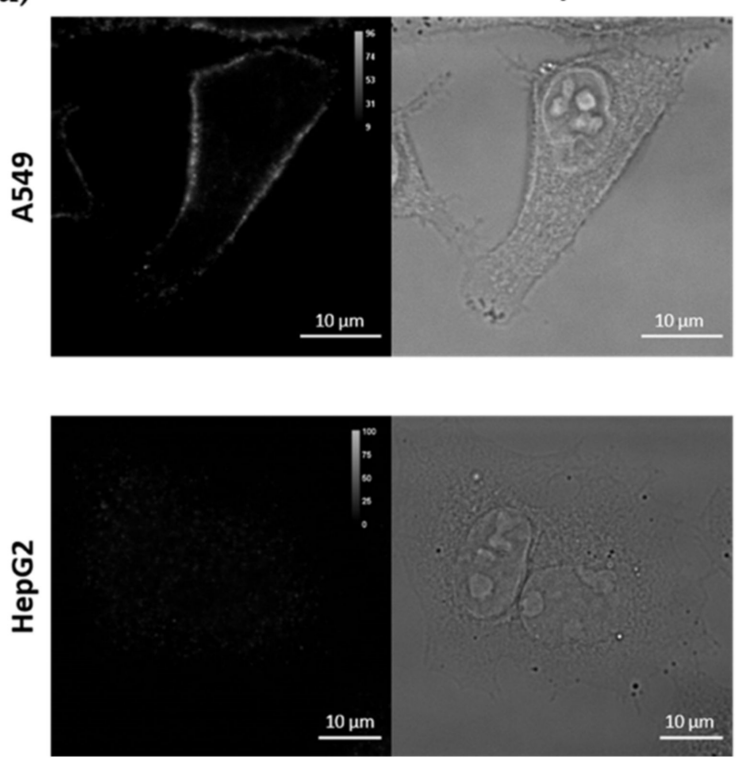

(b)

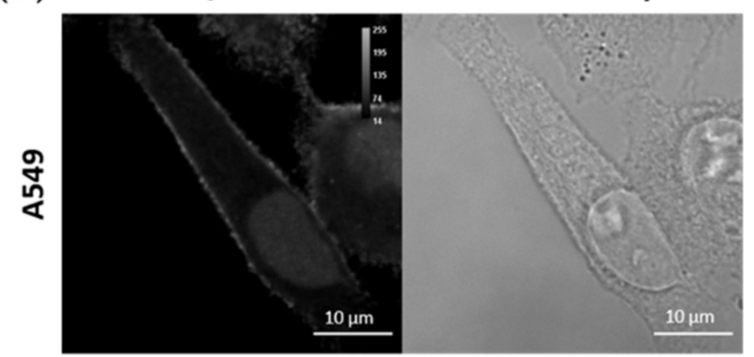

(c)

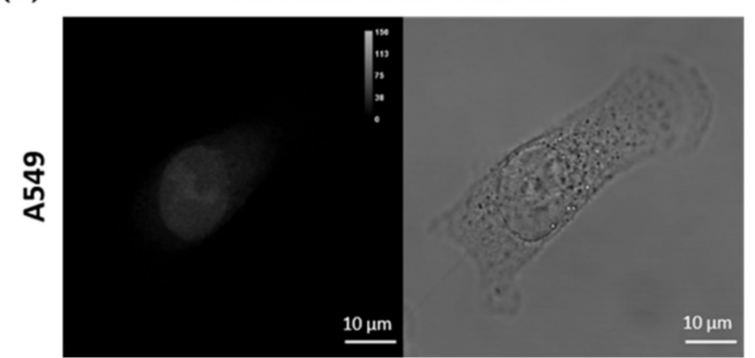

Figure 2. Immunofluorescence (IF) using (a) the unmodified primary rat anti-human CD44 antibody and a secondary donkey anti-rat IgG Alexa Fluor 488 antibody on A549 and HepG2 cells, (b) dual DBCO/Atto488-labelled CD44 antibodies in A549 cells and (c) free NHS ester-Atto488 molecules. Scale bar is $10 \mu \mathrm{m}$.

\subsubsection{Synthesis and Characterization of $\alpha \mathrm{CD} 44$-Conjugated MSNPs}

The antibody was covalently linked on the nanoparticle via copper-free click chemistry between the Azide moiety and the DBCO-labelled antibody (generating $\alpha \mathrm{CD} 44$ PEI-MSNPs, Figure 1c). The developed nanoparticles were characterized using scanning electron microscopy (SEM), atomic force microscopy (AFM), zeta potential measurements, and fluorescence microscopy.

SEM images displayed a uniform size and shape homogeneity of the bare MSNPs, PEI-MSNPs and $\alpha$ CD44-PEI-MSNPs (conjugation with $\alpha$ CD44), with a mean diameter of 118,119 and $124 \mathrm{~nm}$, respectively (Figure $3 \mathrm{a}$ ). The average size of the bare and PEI-coated MSNPs was in agreement with previous reports [49]. Further, a low degree of aggregation was observed in all the samples. Although there was no significant difference in diameter between the bare MSNPs and the PEI-MSNPs, a significant increase could be observed upon antibody functionalization $(p<0.05)$. These results were confirmed with AFM measurements, where an average nanoparticle height of 121,123 and $128 \mathrm{~nm}$ was detected for the MSNPs, PEI-MSNPs and $\alpha$ CD44-PEI-MSNPs, respectively. The corresponding AFM images and plots are displayed in supporting information (Figure S3 in Supplementary Materials). The increase in MSNP height upon antibody functionalization indicated a 
successful attachment to the surface. The small difference can be attributed to the average size of an antibody (in the range of 5 to $15 \mathrm{~nm}$, depending on its orientation).

(a)
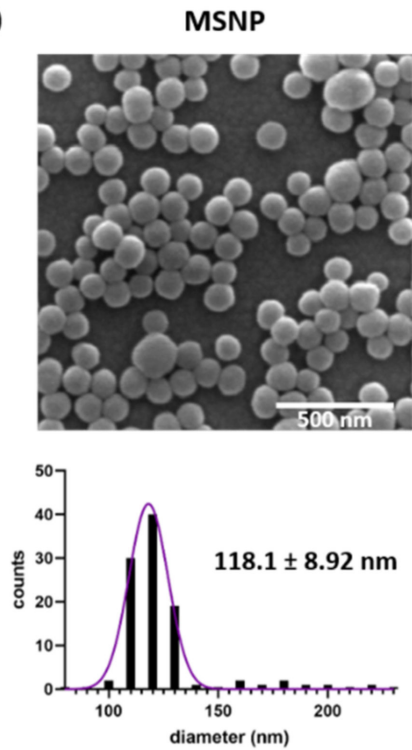

(b)

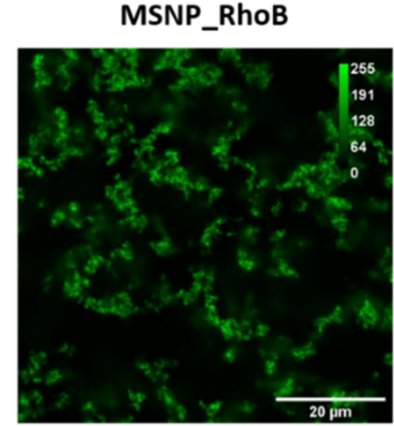

PEI-MSNP
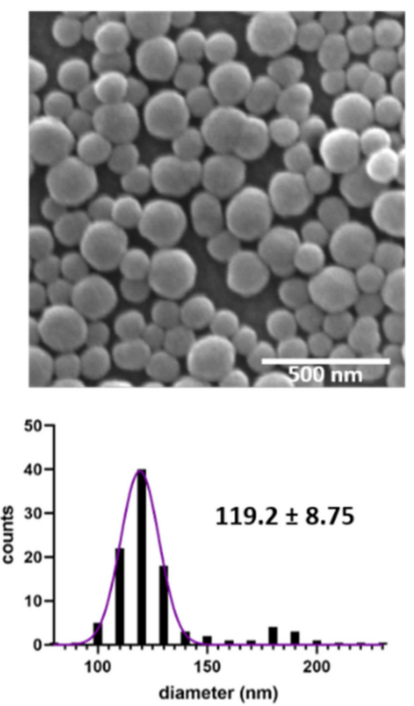

aCD44_Atto488/DBCO

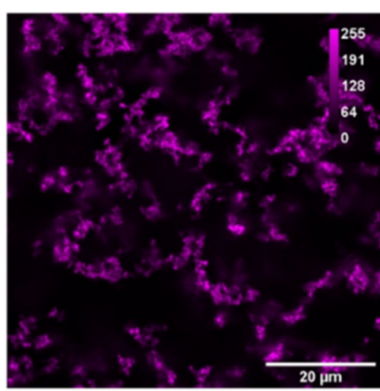

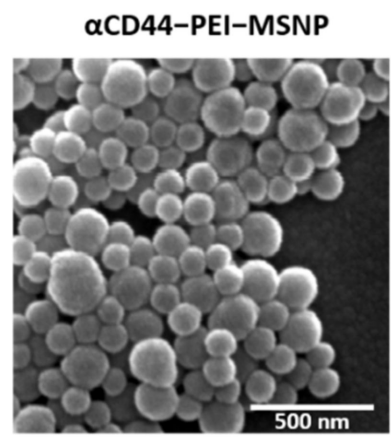

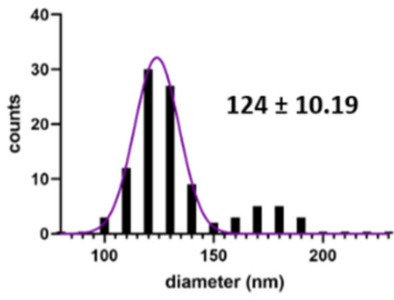

overlay

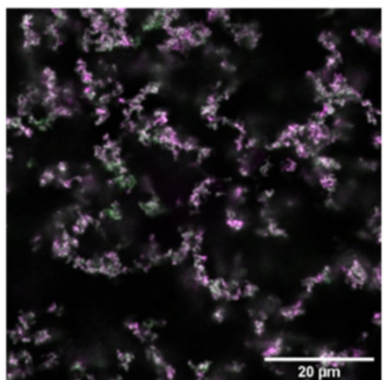

(c)

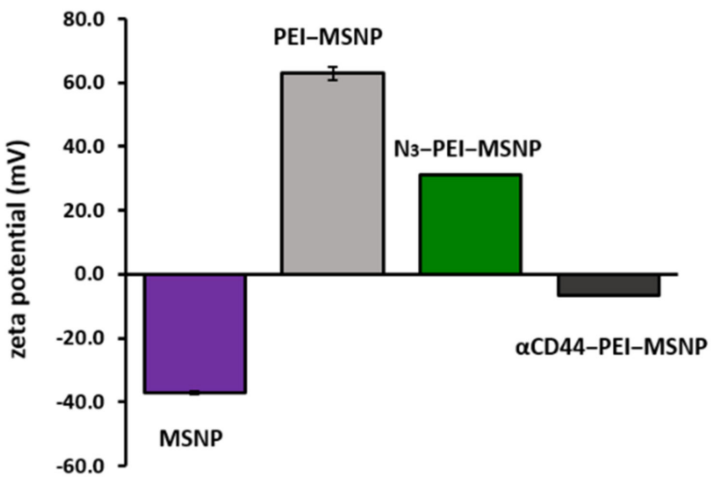

Figure 3. Characterization of bare (MSNPs), PEI-coated (PEI-MSNPs), Azide-functionalized ( $\mathrm{N}_{3}$-PEIMSNPs), and CD44-conjugated ( $\alpha$ CD44-PEI-MSNPs) mesoporous silica nanoparticles. (a) Representative SEM images and size distribution of the imaged particles. Values shown as mean \pm SD. Scale bar is $500 \mathrm{~nm}$. (b) Confocal fluorescence images of $\alpha$ CD44-PEI-MSNPs in which MSNPs were loaded with RhoB (first panel, green), while an Atto488 (and DBCO) label was conjugated to the CD44 antibody (second panel, magenta). An overlay is displayed in the third panel. Scale bar is $20 \mu \mathrm{m}$. (c) Zeta-potential measurements given as mean \pm SD.

Zeta potential measurements were used to follow each step of the functionalization process. Bare MSNPs had a negative charge $(-37.5 \mathrm{mV})$ due to the partially deprotonated hydroxyl groups on the MSNP surface. Upon PEI coating, the zeta potential increased 
to $+63 \mathrm{mV}$ as a result of the presence of amine groups in PEI. Subsequent coupling of the Azide moiety was reflected in a decrease in the zeta potential $(+31 \mathrm{mV})$ (Figure 3c). This decrease can be associated with the formation of an amide upon NHS coupling to the amine. Since the amine was positively charged and the resulting amide was neutral, the reaction promoted a decrease in the overall charge. Finally, a further decrease in zeta potential $(-6.7 \mathrm{mV})$ upon antibody grafting could be observed (Figure 3c). The charge of the nanoparticle after antibody conjugation can be related to the isoelectric point (IEP) of the antibody. Since the IEP of IgG antibodies lies between 6.6 and 7.2 [71], antibodies were expected to be negatively charged at neutral $\mathrm{pH}$, which agreed with our zeta potential results and previously reported results [41,72]. To evaluate the uniformity of antibody conjugation, MSNPs were loaded with a dye (RhoB) before functionalization. Since the antibodies were fluorescently labelled (Atto488), the colocalization between the RhoBloaded MSNPs and the antibody was evaluated with confocal fluorescence microscopy. Figure $3 \mathrm{~b}$ shows a clear overlap between the Atto488-labelled antibody and the RhoBloaded MSNPs. This fluorescence data supported the findings obtained from AFM and the zeta potential measurements, indicating the proper conjugation of the antibody.

The colloidal stability of the antibody-conjugated nanoparticles in the presence of serum was investigated using turbidity measurements. Turbidity measurements are a standard technique to detect particle aggregation, and are well described in literature [73]. This technique is based on the scattering of light by a solution of particles, which corresponds to the turbidity of the suspension. The scattered light is detected via the absorbance at $600 \mathrm{~nm}\left(\mathrm{OD}_{600}\right)$. This results in a value for the optical density of the samples, which is higher for more turbid samples. CD44 antibody-conjugated nanoparticles, dissolved in milli-Q water, FBS, and DMEM medium with $10 \%$ FBS (used for cell culture experiments), were incubated for $24 \mathrm{~h}$ at $37^{\circ} \mathrm{C}$. The $\mathrm{OD}_{600}$ was determined at time 0 and after $24 \mathrm{~h}$ of incubation. The absorbance values are presented in Table S1 (Supplementary Materials) and showed no significant increase in sample turbidity after $24 \mathrm{~h}$ of incubation in all the tested solutions, indicating that the particles were not prone to aggregation in the presence of serum proteins.

\subsection{Selectivity and Efficiency of $\alpha$ CD44-Functionalized Particles \\ 3.2.1. Targeting Capability of $\alpha$ CD44-PEI-MSNPs}

To assess the targeting capability of the antibody-conjugated MSNPs towards CD44overexpressing cells, FITC-encapsulated MSNPs were used to monitor the cellular uptake via fluorescence microscopy. In this case, targeting capability refers to the selective uptake of the CD44 antibody-conjugated nanoparticles to CD44 receptor-overexpressing cells. The targeting efficiency was tested by comparing the number of nanoparticles internalized in A549 cells (human lung carcinoma cells, with CD44 receptor overexpression [74]) and HepG2 cells (liver carcinoma, with low CD44 receptor expression [75]). Both cell lines were incubated for $6 \mathrm{~h}$ with MSNPs presenting different functionalization: no coating (MSNPs), only a PEI coating (PEI-MSNP) and both the PEI and antibody functionalization ( $\alpha$ CD44PEI-MSNPs). As a control, the cells were also incubated with a nanoparticle conjugated to a non-specific IgG antibody (IgG-PEI-MSNP). Afterwards, the medium was refreshed to avoid further nanoparticle internalization and the cells were incubated overnight $(24 \mathrm{~h}$ incubation in total). The internalization was quantified by confocal fluorescence imaging after staining the plasma membrane with a lipid intercalating dye (DiR). The fluorescence images are shown in Figure 4. The uptake of bare MSNPs was minimal in both cell lines (Figure 4a,e), while a coating with PEI resulted in an increase in internalization in both A549 and HepG2 (Figure 4b,f). The increase in cellular uptake of nanoparticles upon PEI functionalization was in agreement with previous reports and can be attributed to the positive charge of PEI-MSNPs, leading to a higher interaction with the negatively charged plasma membrane, which facilitates nanoparticle internalization [49,51,76,77]. It is important to note that this enhanced uptake of PEI-coated MSNPs was cell line unspecific. Thanks to the charge drop (from $+63 \mathrm{mV}$ to $-6.7 \mathrm{mV}$ ), this unspecific internalization was minimized 
upon antibody conjugation to MSNPs. As such, uptake of $\alpha$ CD44-PEI-MSNPs in HepG2 was lower, similar to the internalization of bare MSNP (Figure 4g). On the other hand, A549 cells incubated with $\alpha$ CD44-PEI-MSNPs displayed a high number of internalized particles, especially when compared to bare MSNP (Figure 4e). A quantitative mean fluorescence intensity of the internalized nanoparticles revealed that there were 20 times more particles inside A549 cells when compared to HepG2 cells (Figure 4i). Incubation with the non-specific IgG-conjugated nanoparticles resulted in an uptake comparable to bare MSNPs in both A549 and HepG2 cells. This low internalization could be explained by the non-specificity of this antibody to membrane proteins in these cell lines and the negative zeta potential $(-11.8 \mathrm{mV})$ of the resulting IgG-conjugated nanoparticles (which minimized their non-specific uptake). To assure that the observed increase in cellular uptake in CD44overexpressing cells was not linked to the specific cell lines used, we checked the uptake of $\alpha$ CD44-PEI-MSNPs in two fibroblast cell lines, NIH3T3 (mouse embryonic fibroblasts with a low CD44 expression [78,79]) and BJ1-hTERT (human fibroblasts with high CD44 expression $[80,81])$, using the same experimental approach (Figure S4). The respective CD44 expression in the two cell lines was validated with a standard immunofluorescence staining of CD44 (Figure S5, Supplementary Materials). The discrepancy between the uptake of $\alpha$ CD44-PEI-MSNPs in fibroblasts with different expression levels of CD44 confirmed the targeting efficiency of our nanoparticles after conjugation with the CD44 antibody.

\subsubsection{Intracellular Trafficking}

One of the main bottlenecks faced by DDSs is their entrapment in acidic vesicles and subsequent degradation, significantly limiting the overall efficiency of the DDS [82-84]. To this end, strategies have been developed to facilitate an endosomal escape, releasing the nanoparticles (or their cargo) into the cytoplasm. We previously showed that the addition of a PEI shell leads to the release of the nanoparticles in the cytoplasm [49]. To verify that conjugation to an antibody does not affect the endosomal escape capability of the PEI layer, the co-localization of $\alpha$ CD44-PEI-MSNPs with lysosomes was monitored using fluorescence microscopy. Briefly, A549 cells were incubated with RhoB-loaded $\alpha$ CD44-PEIMSNPs for $24 \mathrm{~h}$, after which the medium of the samples was refreshed, in order to avoid further nanoparticle internalization (i.e., only nanoparticles that were endocytosed within the first $24 \mathrm{~h}$ of incubation were followed). At each time point (24, 48 and $72 \mathrm{~h}$ after particle addition), the acidic vesicles were stained with LysoTracker Deep Red and the samples were imaged. Figure 5 shows representative fluorescence images at the different time points. To quantify the co-localization between the acidic vesicles and the $\alpha C D 44-P E I-M S N P s$ through time, the Manders' co-localization coefficient was calculated (Figure S6, Supplementary Materials). Briefly, an intensity-based threshold was used to calculate the areas of the image corresponding to nanoparticles and to lysosomes. The Manders' coefficient (MC) calculates the degree of overlap between objects in different channels (with 0 being no overlap and 1 indicating a complete overlap). Fluorescence images showed that, within $24 \mathrm{~h}$, almost all nanoparticles were located inside the acidic vesicles (Figure 5a). While at 24 and $48 \mathrm{~h}$, no relevant escape was observed with MC of 0.88 and 0.82 (Figure S6), a significant decrease in the co-localization of nanoparticles and lysosomes was found after $72 \mathrm{~h}$ (MC of 0.66), indicating that after $72 \mathrm{~h}$ a considerable number of $\alpha$ CD44-PEI-MSNPs were localized outside the lysosomes (Figure 5c). Overall, these results suggest that the presence of $\alpha \mathrm{CD} 44$ on the surface of the nanoparticles does not affect the endosomolytic activity of the PEI coating as most of nanoparticles were able to dissociate from the lysosomes within $72 \mathrm{~h}$. This was validated by the significant difference in MC found between 48 and $72 \mathrm{~h}$ (Figure S6). The endosomal escape rate was, however, slower than MSNPs coated with only PEI, where the majority of the particles escaped the lysosomes within $48 \mathrm{~h}$ (previously reported by our group [49]). Since the proton sponge effect is linked to the amine groups of the PEI, this delay might be associated with the reduced number of amine groups available, as part of these are used for N3 functionalization and further coupling to the antibodies. 

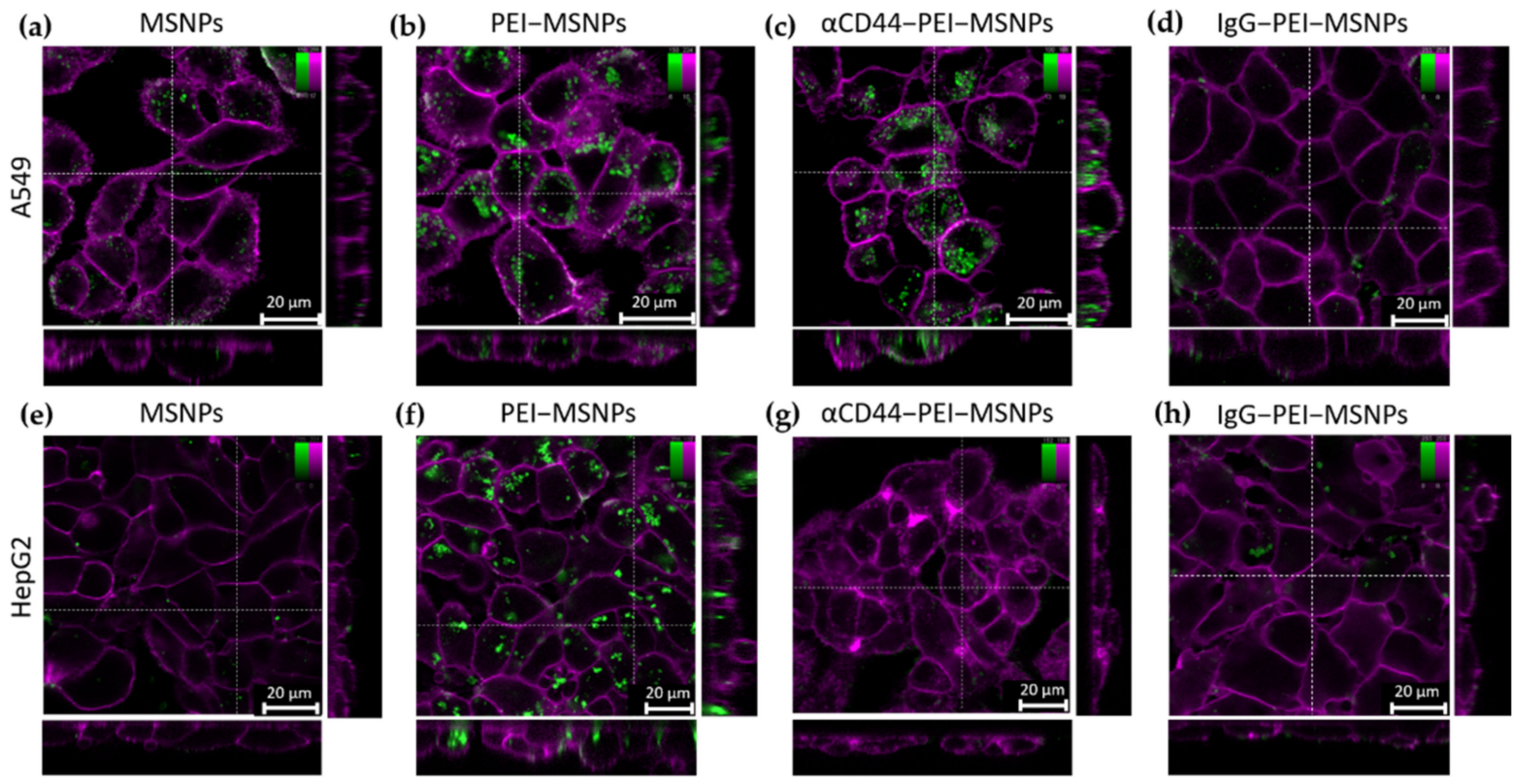

(f) PEI-MSNPS

(g) $\alpha C D 44-P E I-M S N P S$
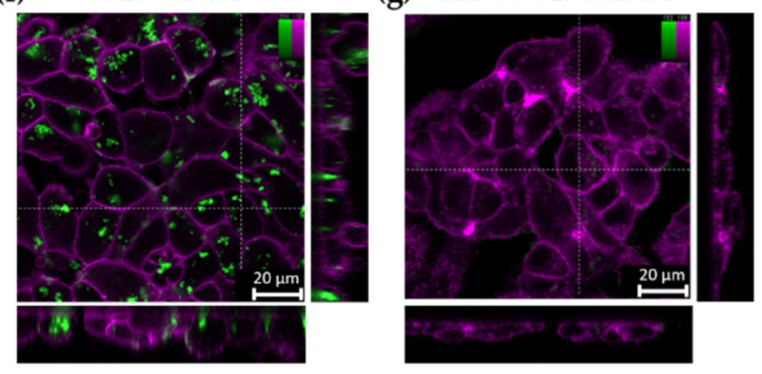

(h) IgG-PEI-MSNPS

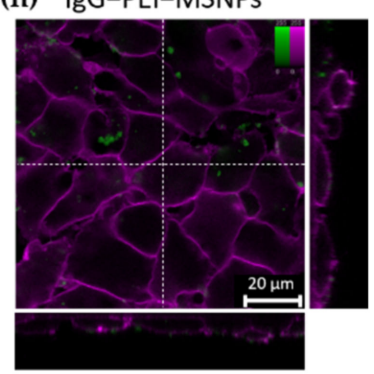

(i)

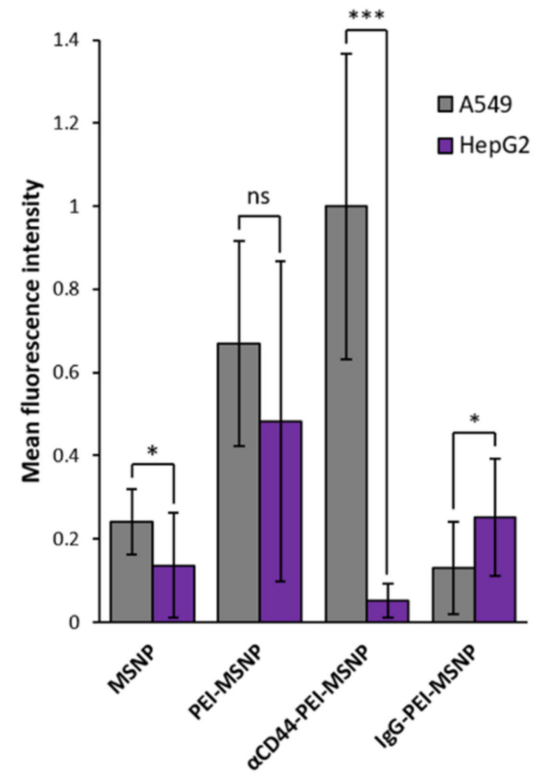

Figure 4. Confocal fluorescence microscopy images showing the influence of different MSNP coatings on the uptake of nanoparticles in A549 and HepG2 cells. Internalization of bare MSNP (a,e), PEI-coated MSNPs (PEI-MSNP, panels (b,f)), CD44-functionalized MSNPs ( $\alpha$ CD44-PEI-MSNP, panels (c,g)), and IgG-functionalized MSNPs (IgG-PEI-MSNP, panels $\mathrm{d}, \mathrm{h})$ in A549 cells $(\mathbf{a}-\mathbf{d})$ and HepG2 cells (e-h). Nanoparticles were loaded with Fluorescein (FITC, green) and the plasma membrane was stained with $\mathrm{DiR}$ (magenta). The central square represents a single xy plane, while the bottom and left panels are the $\mathrm{xz}$ and yz cross-sections, indicated by the dashed lines. Scale bar is $20 \mu \mathrm{M}$; color bars display the intensity values. (i) Normalized mean fluorescence intensity of MSNP, PEI-MSNP, $\alpha$ CD44-PEI-MSNPs, and IgG-PEI-MSNPs internalized in A549 and HepG2 (20 cells per condition). The data were analyzed using Fiji (see Methods section for details). With ns: not significant, ${ }^{*}(p<0.05),{ }^{* * *}(p<0.001)$. 


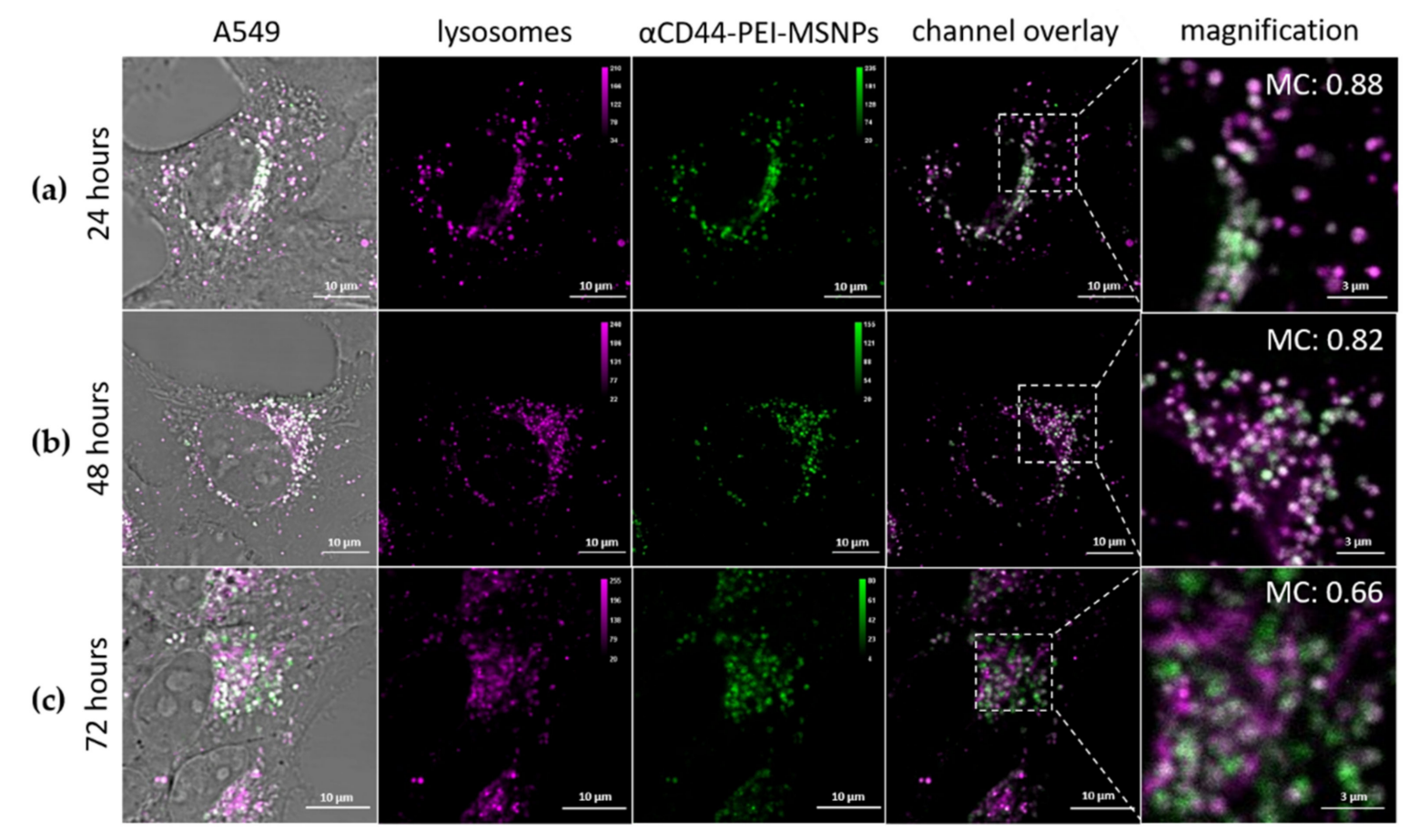

Figure 5. Intracellular localization of RhoB-loaded $\alpha$ CD44-PEI-MSNPs (green) with respect to the lysosomes (Lysotracker Deep Red, magenta) over time. A549 cells were incubated with $\alpha$ CD44-PEI-MSNPs (final concentration of $50 \mu \mathrm{g} / \mathrm{mL}$ ) for (a) $24 \mathrm{~h} \mathrm{(b)} 48 \mathrm{~h}$ and (c) $72 \mathrm{~h}$. The first column shows a complete merge including the transmission image, also displaying the cell areas. In the second and third columns, the lysosomes and nanoparticles are depicted, in purple and green, respectively. In the fourth and fifth columns, a channel overlay and respective magnification are shown. Scale bar is $10 \mu \mathrm{m}$ in the main images and $3 \mu \mathrm{m}$ in the magnified images.

\subsubsection{Intracellular Release of Doxorubicin}

As shown in the previous section, a considerable number of the internalized $\alpha \mathrm{CD} 44$ PEI-MSNPs were able to escape the acidic vesicles. Aside from the ability to escape the lysosomes, a higher efficiency requires that enough cargo can be released into the cytoplasm in a controlled fashion. To monitor the drug release after cellular uptake, doxorubicin was used as drug model and encapsulated in the pores of MSNPs prior to coating ( $\alpha$ CD44-PEIMSNPs_Dox). Dox is a cytostatic anticancer drug that is used to treat different types of cancer, for instance, leukemia, lymphoma, and breast cancer. Its mechanism of action is based on the intercalation with the DNA, resulting in cell death [85]. Due to the fluorescent nature of Dox, its intracellular localization could be monitored over time with confocal fluorescence microscopy. To show that $\alpha$ CD44-PEI-MSNPs_Dox carried Dox into the target cell and exhibited a controlled intracellular drug release, A549 cells were incubated with $\alpha$ CD44-PEI-MSNPs_Dox for 8, 24, 48 and $72 \mathrm{~h}$. To avoid further nanoparticle internalization, the medium of the samples was refreshed $24 \mathrm{~h}$ after the addition of the nanoparticles. The acidic compartments were stained with LysoTracker Deep Red (magenta, Figure 6) to analyze the cargo (Dox, cyan) release/leakage from the lysosomes. While after 8 and $24 \mathrm{~h}$, most of the Dox was still retained inside lysosomes (indicated by the high overlap between the Dox and the lysosomes, Figure 6a,b), increasing amounts of Dox discharged into the cytosol were observed after 48 and $72 \mathrm{~h}$ (Figure $6 \mathrm{c}, \mathrm{d}$ ). The overlap between the acidic vesicles and Dox molecules at 8 and $24 \mathrm{~h}$ indicated that, at this time point, Dox was presumably still inside the pores of the MSNPs or being slowly released inside the acidic vesicles. At an acidic $\mathrm{pH}$, the silica hydroxyl groups are protonated, hindering the electrostatic interaction between the PEI and the silica surface. Therefore, we hypothesized that the decreased $\mathrm{pH}$ inside the lysosomes aids in the release of the shell and facilitates the consequent Dox release from the mesoporous silica pores. Accordingly, increasing 
amounts of Dox were detected in the cytoplasm over 48 to $72 \mathrm{~h}$ (Figure 6c,d). Moreover, as shown in Figure 6d, the cells' morphology suggested cellular death, indicating that the cells were being killed by the successful release of the drug.

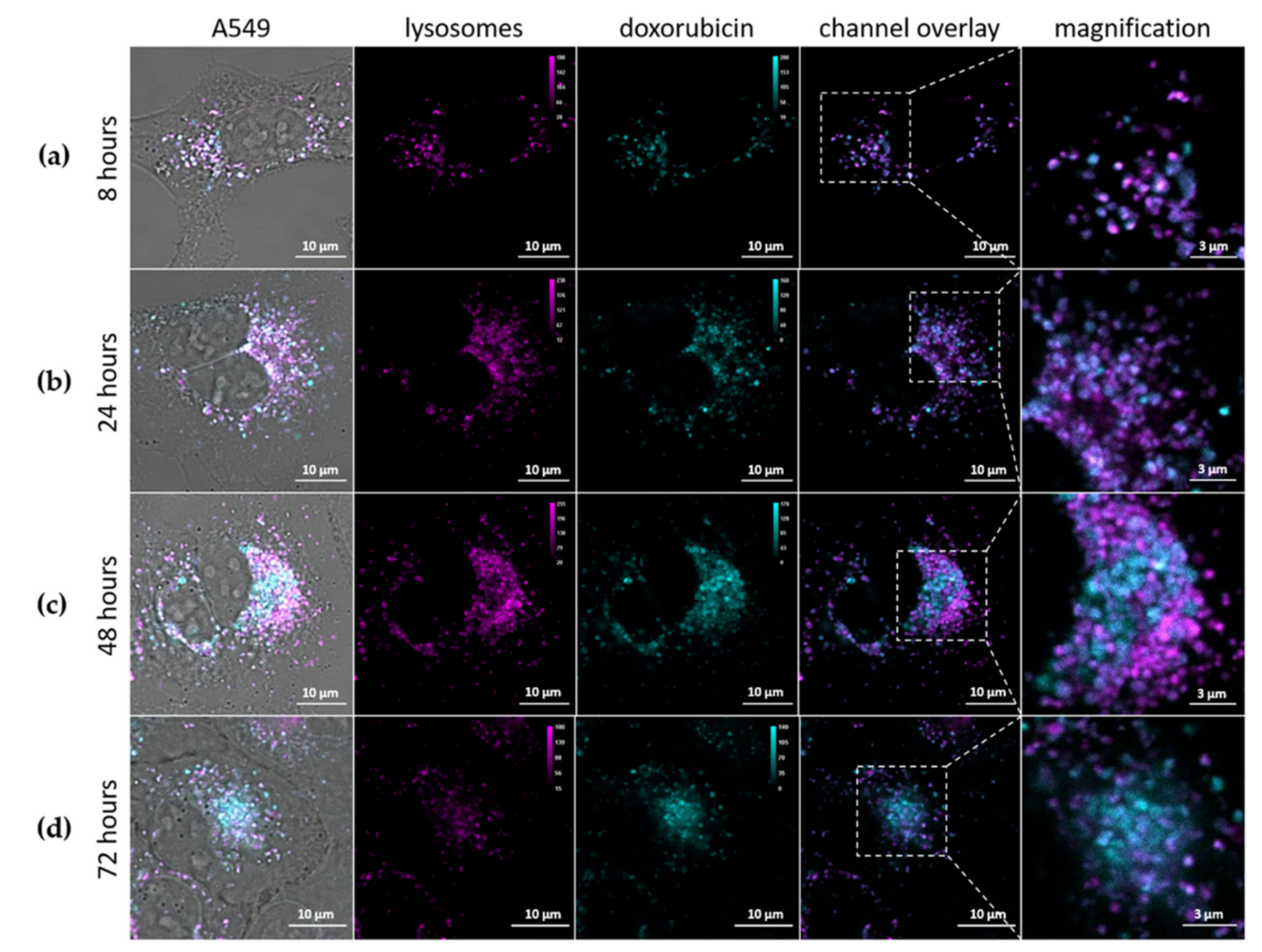

Figure 6. Intracellular release of Dox (cyan) from $\alpha$ CD44-PEI-MSNPs_Dox with respect to the lysosomes (magenta) over time. A549 cells were incubated with $\alpha$ CD44-PEI-MSNPs_Dox (final concentration of $50 \mu \mathrm{g} / \mathrm{mL}$ ) for (a) $8 \mathrm{~h}$, (b) $24 \mathrm{~h}$, (c) $48 \mathrm{~h}$ and (d) $72 \mathrm{~h}$. The first column shows a complete merge including the transmission image, also displaying the cell contours. In the second and third columns, the lysosomes and Dox are depicted, in pink and cyan, respectively. In the fourth and fifth columns, a channel overlay and respective magnification are shown. Scale bar is $10 \mu \mathrm{m}$ in the main images and $3 \mu \mathrm{m}$ in the magnified images.

\subsubsection{Cytotoxicity Studies}

To evaluate the cytotoxicity of the antibody-coated MSNPs, the viability of A549 and HepG2 cells was investigated after $72 \mathrm{~h}$ of incubation with pure Dox, Dox-loaded nanoparticles ( $\alpha$ CD44-PEI-MSNPs@Dox), and empty nanoparticles ( $\alpha$ CD44-PEI-MSNPs). After $24 \mathrm{~h}$ of incubation with the nanoparticle/drug solution, the medium was refreshed to avoid the continued uptake of nanoparticles/drug in the medium and to better mimic the physiological scenario of nanoparticle clearing from the bloodstream. Different concentrations of Dox and nanoparticles were added, ranging from $25 \mathrm{nM}$ to $200 \mathrm{nM}$ for free Dox and 25 to $100 \mu \mathrm{g} / \mathrm{mL}$ for the nanoparticles (Figure 7). For both cell lines, empty $\alpha$ CD44PEI-MSNPs could be considered non-toxic, reaching a minimum of $92 \%$ cell viability at the highest concentration $(100 \mu \mathrm{g} / \mathrm{mL})$. For both cell lines, a dose-dependent response on the cell viability was observed for free Dox. We found an evident difference in the cell-killing effect between the free Dox and the Dox-loaded nanoparticles $(p<0.05)$ for A549 cells. Dox-loaded $\alpha$ CD44-PEI-MSNPs exhibited dose-dependent cytotoxic effects for A549 (reaching a minimum of $38 \%$ of viability at the highest concentration). This enhanced cytotoxicity of the Dox-loaded nanoparticles is linked to the high internalization rate of 
the $\alpha$ CD44-PEI-MSNPs followed by endosomal release and specific drug release in the cytoplasm. Importantly, the negligible internalization of $\alpha$ CD44-PEI-MSNPs in HepG2 cells resulted in the absence of toxic effects when using Dox-loaded particles (viability similar to the control). The high cell viability also indicates that the drug did not leak from the nanoparticles into the extracellular environment.

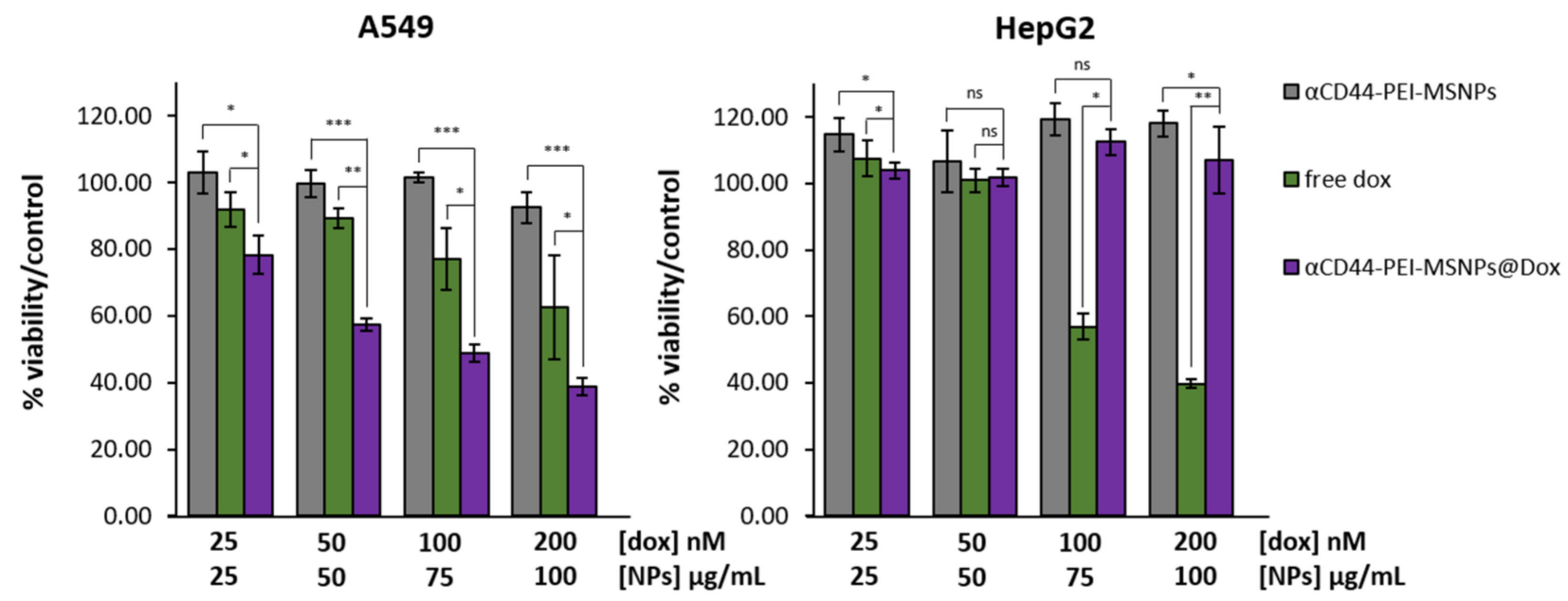

Figure 7. Viability of A549 and HepG2 cells after 72-h incubation with different concentrations of free Dox, Dox-loaded $\alpha$ CD44-PEI-MSNPs, and empty $\alpha$ CD44-PEI-MSNPs. A549 and HepG2 cells that were not incubated with particles or drug were used as a control and represent 100\% viability (data not shown). Dox concentrations are expressed in nM while nanoparticle concentrations are in $\mu \mathrm{g} / \mathrm{mL}$. Estimated Dox concentration loaded in the nanoparticles was $50 \mu \mathrm{M}$. Error bars indicate $\pm \mathrm{SD}$, with ns meaning not significant; ${ }^{*}(p<0.05),{ }^{* *}(p<0.01)$, and ${ }^{* * *}(p<0.001), \mathrm{n}=4$.

From these results, it can be concluded that Dox-loaded $\alpha$ CD44-PEI-MSNPs exhibited high toxicity to CD44-overexpressing cells only (higher than free Dox), while only limited to no toxicity was observed for the empty carrier. Consequently, a satisfying therapeutic efficiency can be concluded, through an efficient nanoparticle internalization and high drug payload delivery targeted to the cancer cell cytosol.

\subsection{The $\alpha E G F R$-Conjugated Nanoparticles}

To prove the versatility of our antibody coating strategy, we targeted next a second cancer marker, EGFR. EGFR overexpression is related to different types of cancers and is often associated to a poor prognosis for the patient. Especially in glioblastoma, lung, and breast cancers, where EGFR stimulates tumor growth [44]. To this end, EGFR has emerged as a popular target for cancer cell-specific therapies. As a result, many nanoparticles targeting EGFR were developed, either via nanoparticle conjugation with its ligand, EGF, or by attaching EGFR antibodies [86-89].

\subsubsection{Labelling of the EGFR Antibodies}

For labelling the EGFR antibodies, the same method was used as for the CD44 antibodies (Section 3.1.2). Similarly, labelling with DBCO was performed, enabling the conjugation of DBCO-EGFR antibodies to the Azide-coated nanoparticles. For fluorescence microscopy purposes, the EGFR antibodies were also conjugated to a dye (Atto565). The dual labelling of the EGFR antibodies with DBCO and Atto565 was carried out via an NHS ester coupling reaction with the antibodies' lysine residues (as described in Methods). We checked whether the specificity of the EGFR antibody was retained after dual labelling (with Atto565 and DBCO) by performing immunofluorescence on two cell lines, A431 and Hek293 cells, presenting high and low expression of EGFR, respectively [90,91]. First, the EGFR expression in the chosen cell lines, A431 and Hek293, was determined via immunofluorescence with the unmodified EGFR antibody (followed by staining with a fluorescently labelled secondary antibody, goat-anti-mouse IgG AF488). As shown in 
Figure 8a, EGFR was visualized on the plasma membrane of A431 cells, while no EGFR could be detected in Hek293 cells. A431 cells stained with the DBCO/Atto565-labelled EGFR antibody also displayed the plasma membrane-localized signal, proving that the specificity of the EGFR antibody was not hindered by our labelling protocol (Figure $8 \mathrm{~b}$ ). A nuclear background could be observed, associated to free Atto565 molecules, similar to what was observed for the Atto488 molecules (see Section 3.1.2).

(a)
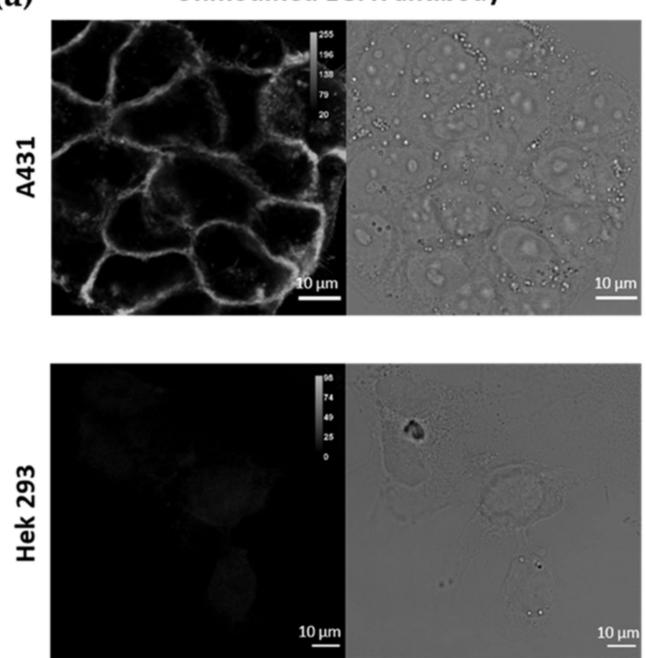

(b) DBCO/Atto656 labeled EGFR antibody

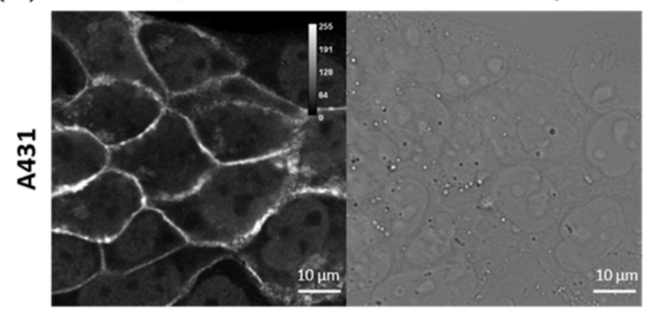

Figure 8. Immunofluorescence (IF) using (a) the unmodified primary mouse anti-human EGFR antibody followed by a labelled secondary antibody, goat anti-mouse IgG AF488, on A431 and Hek293 cells; (b) DBCO/Atto565-labelled EGFR antibodies in A431 cells. Scale bar is $10 \mu \mathrm{m}$.

\subsubsection{Synthesis and Characterization of $\alpha$ EGFR-Conjugated MSNPs}

The EGFR antibody was attached to the Azide-coated nanoparticles via the same approach ( $\alpha$ EGFR-PEI-MSNPs). Since the EGFR antibody was labelled with an Atto565 dye (as described in the previous section), to avoid spectral overlap during fluorescence microscopy studies, Azide-conjugated nanoparticles were labelled with Fluorescein (FITC). FITC was covalently attached to the silica matrix, as stated in the Methods section. The resulting $\alpha$ EGFR-conjugated nanoparticles were characterized via SEM, AFM, zeta potential measurements, and fluorescence microscopy.

Similar to $\alpha$ CD44-conjugated particles, $\alpha$ EGFR-PEI-MSNPs displayed a uniform size and shape homogeneity (Figure 9a). With a mean diameter of $122 \mathrm{~nm}$ (as derived from the SEM data), $\alpha$ EGFR-PEI-MSNPs were significantly bigger than the PEI-MSNPs (Figure 3a) $(p<0.05)$ because of the EGFR layer. AFM measurements revealed an average nanoparticle diameter of $127 \mathrm{~nm}$, which agreed with the SEM results (Figure S3). Zeta potential measurements were performed to check the different steps of nanoparticle functionalization. The zeta potential data of the bare MSNPs, PEI-grafted MSNPs (PEI-MSNPs), and Azideconjugated MSNPs ( $\mathrm{N}_{3}-\mathrm{PEI}-\mathrm{MSNPs}$ ) were already discussed in Section 3.1.3. (Figure 3c). The $\alpha$ EGFR-PEI-MSNPs displayed a negative zeta potential $(-11.6 \mathrm{mV})$, similar to the one of the MNSPs after conjugation with the CD44 antibody ( $\alpha$ CD44-PEI-MSNPs, $-6.7 \mathrm{mV}$ ) (Figure 9b). Additionally, in order to confirm uniform binding of the EGFR antibody, MSNPs were encapsulated with a fluorescent dye (FITC), while the EGFR antibody was labelled with another dye (Atto565). Accordingly, the co-localization between the EGFR antibody and the MSNPs could be determined via confocal fluorescence microscopy measurements. These data confirmed proper attachment of the EGFR antibody and uniform coverage of the nanoparticles with antibody molecules (Figure 9c). 
(a)
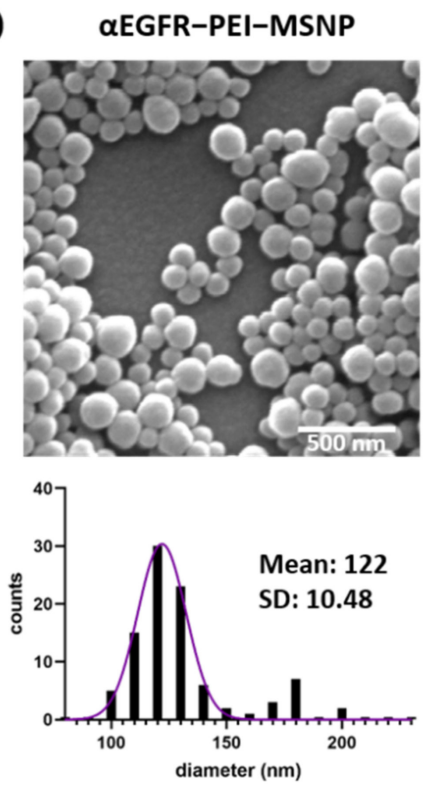

(c)

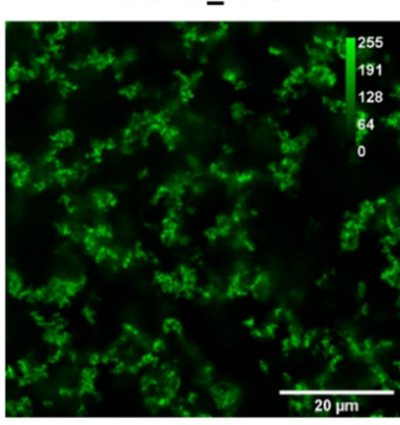

(b)

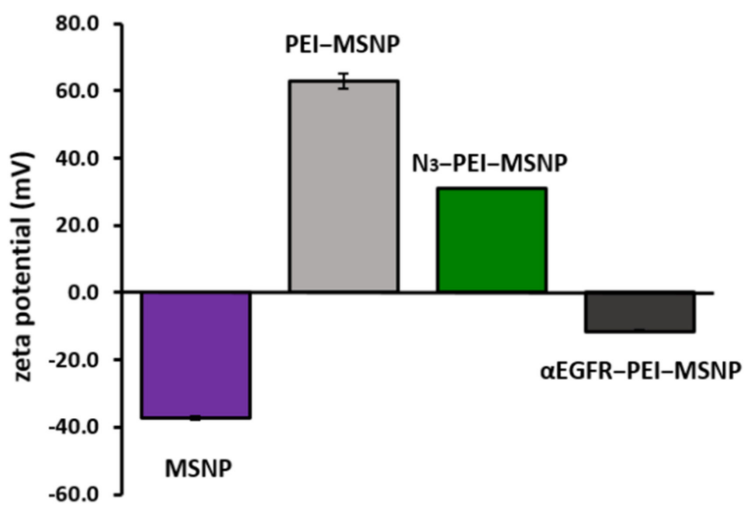

QEGFR_Atto565/DBCO

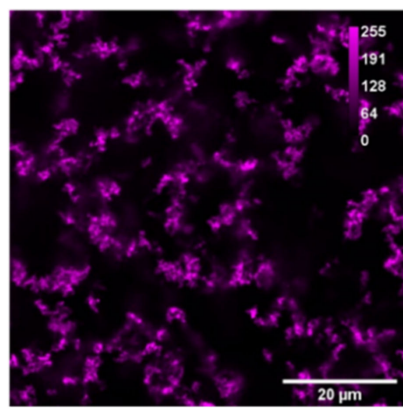

overlay

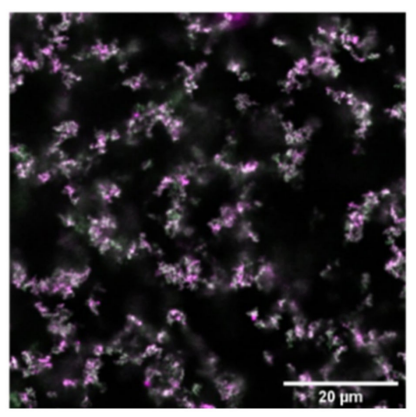

Figure 9. Characterization of EGFR-conjugated ( $\alpha$ EGFR-PEI-MSNPs) mesoporous silica nanoparticles. (a) Representative SEM image and size distribution of the imaged particles (values shown as mean \pm SD). Scale bar is $500 \mathrm{~nm}$. (b) Zeta-potential measurements. (c) Confocal fluorescence images of sedimented nanoparticles on glass showing the overlay (third panel) of FITC-encapsulated MSNPs (first panel, green) and the Atto565/DBCO-labelled EGFR antibody (second panel, magenta).

\subsubsection{Targeting Capability of $\alpha$ EGFR-PEI-MSNPs}

The uptake of nanoparticles with different coatings (MSNPs, PEI-MSNPs, $\alpha$ EGFRPEI-MSNPs, and IgG-PEI-MSNP) was compared between A431 (epidermoid carcinoma with high EGFR expression [86]) and Hek293 cells (human embryonic kidney cells with low EGFR expression [91]). In agreement with the results of the preceding experiment, bare MSNPs were internalized in A431 and Hek293 in a low amount (Figure 10a,e), and a similar increase in uptake could be detected for MSNPs with a PEI layer (Figure 10b,f). As predicted, conjugation of the EGFR antibody resulted in a significant discrepancy in particle uptake between A431 and Hek293 cells (Figure 10c,g,i). Hek293 displayed a similar uptake behavior for the $\alpha$ EGFR-PEI-MSNPs and the bare MSNPs (Figure 10g) while, in A431 cells, there was an obvious increase in the number of $\alpha$ EGFR-PEI-MSNPs internalized, especially when compared to bare MSNPs (Figure 10c). This increase can be attributed to the specific recognition of the EGFR receptor by the $\alpha$ EGFR-PEI-MSNPs, proving cell specificity of these nanoparticles. Similar to A549 and HepG2, the incubation of A431 and Hek239 cells with the non-specific IgG-conjugated nanoparticles resulted in an internalization comparable to bare nanoparticles. As mentioned in Section 3.2.2, this is a consequence of the non-specificity of the IgG towards membrane proteins expressed in these cell lines and the negative zeta potential $(-11.8 \mathrm{mV})$ of the resulting IgG-conjugated nanoparticle (minimum non-specific uptake). To further evaluate the specificity of the 
antibody-conjugated nanoparticles, expression of the EGFR receptor in Hek293 was induced by transiently transfecting Hek293 cells with a plasmid encoding an EGFR-HaloTag ${ }^{\circledR}$ fusion construct (see Methods section for details). A fluorescent ligand (Alexa Fluor 488 HaloTag $^{\circledR}$ ligand) was used to identify the EGFR-expressing Hek293 cells via confocal fluorescence microscopy (Figure S7 in Supplementary Materials). Quantitative analysis of the fluorescence intensity revealed that Hek239 cells expressing EGFR molecules exhibited a higher uptake of $\alpha$ EGFR-PEI-MSNPs (Figure 10i). This demonstrates that the internalization of $\alpha$ EGFR-PEI-MSNPs is linked to the presence of the EGFR receptor on the cell membrane, further confirming the selectivity of the developed nanoparticles.
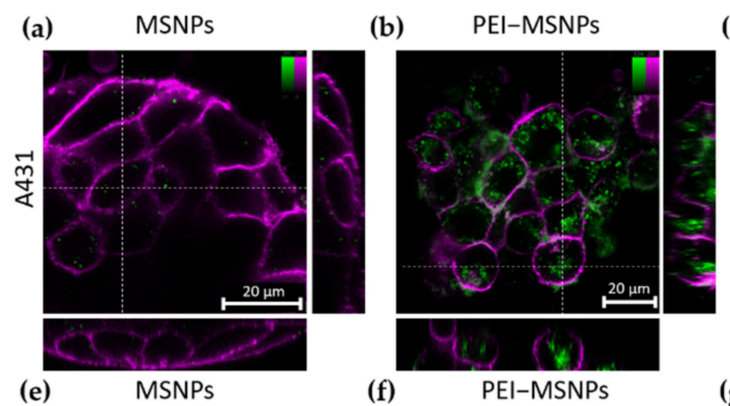

(c) $\alpha$ EGFR-PEI-MSNPs (d) IgG-PEI-MSNPS
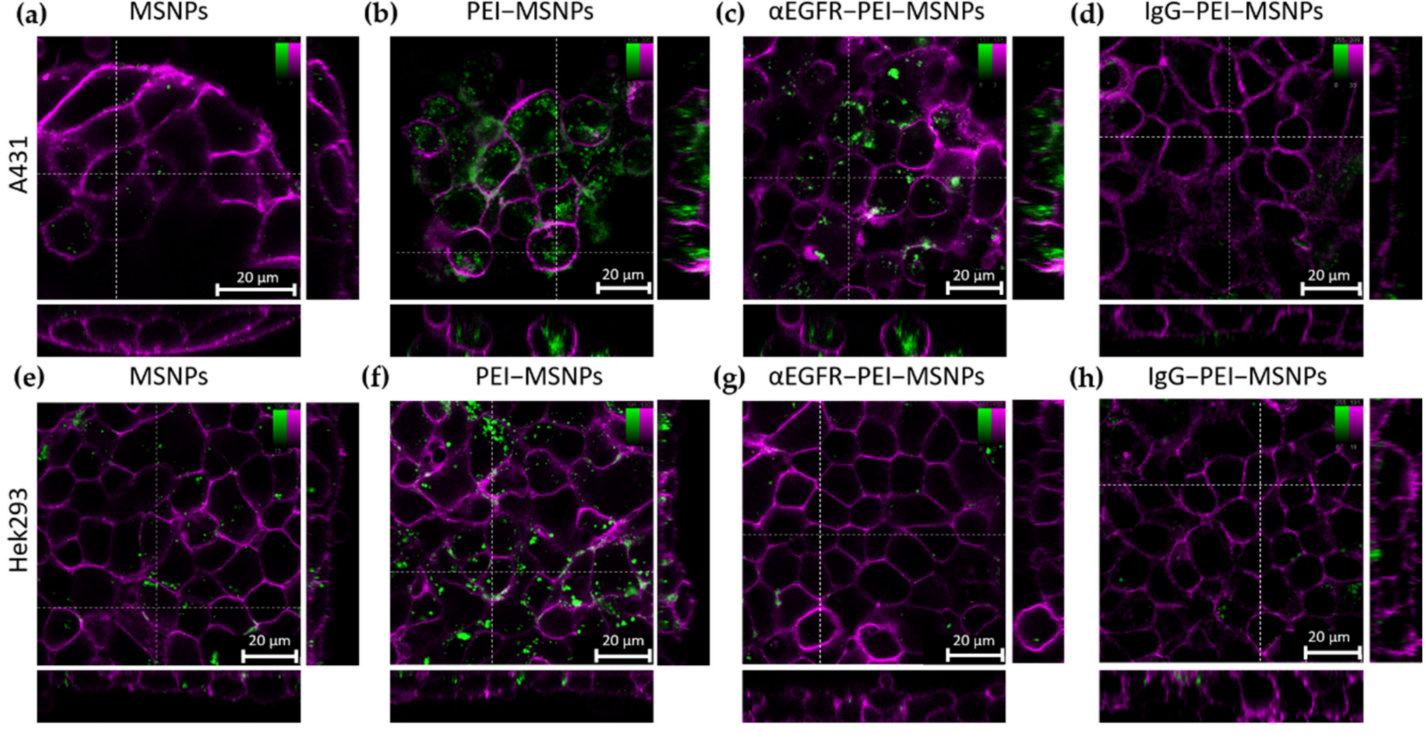

(g) aEGFR-PEI-MSNPS

(h) IgG-PEI-MSNPS

(i)

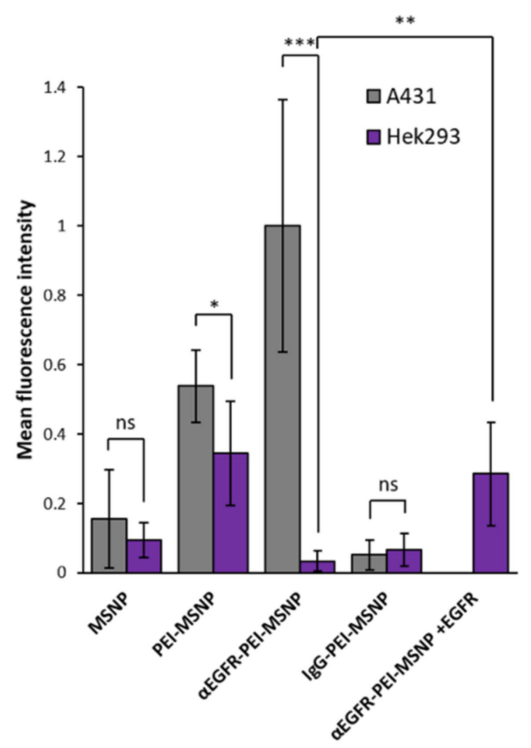

Figure 10. Confocal fluorescence microscopy stacks showing the influence of different MSNP coatings in A431 and Hek293 cells. (a-d) Internalization of MSNP, PEI-MSNP, $\alpha$ EGFR-PEI-MSNP, and IgG-PEI-MSNP in A431 cells (from left to right). (e-h) Internalization of MSNP, PEI-MSNP, $\alpha$ EGFR-PEI-MSNP, and IgG-PEI-MSNP in Hek293 cells (from left to right). Nanoparticles (encapsulated with fluorescein) are displayed in green and the plasma membrane is stained with DiR (magenta). Scale bar is $20 \mu \mathrm{M}$; color bars display the intensity values. (i) Normalized mean fluorescence intensity of MSNP, PEI-MSNP, $\alpha$ EGFR-PEI-MSNPs, and IgG-PEI-MSNPs internalized in A431 and Hek293 cells and $\alpha$ EGFR-PEI-MSNPs in Hek293 cells transiently expressing EGFR (Hek293 + EGFR, 20 cells per condition). The data were analyzed using Fiji (see Methods section for details). With ns: not significant, ${ }^{*}(p<0.05),{ }^{* *}(p<0.01)$, and ${ }^{* *}(p<0.001)$. 


\section{Conclusions}

In this work, we showed a facile method for the conjugation of different antibodies to nanoparticles using copper-free click chemistry. Here, mesoporous silica nanoparticles (MSNPs) were chosen as drug carriers and the base for further functionalization; however, other nanoparticles can be used. Similarly, the Doxorubicin loaded inside the MSNPs can be substituted by other drugs for different therapeutic applications.

The first step in our approach was to coat the nanoparticles with a PEI layer. The PEI amine groups provide the anchor for the covalent attachment of an Azide moiety, to which the DBCO-labelled antibodies were covalently linked via a simple click reaction. Importantly, click chemistry can be carried out under physiological conditions, without using any catalyst. Furthermore, the presence of the PEI layer reduced the effect of nanoparticle entrapment in the acidic vesicles (by taking advantage of the proton sponge effect) and supported the controlled drug release into the cancer cell.

All existing antibodies can be labeled with a DBCO group in the same controllable way (via an NHS-ester coupling with their amine groups) and their conjugation to the nanoparticles only requires the presence of an amine group on the nanoparticle surface. Therefore, this approach to produce antibody-conjugated nanoparticles is extremely versatile and has the potential to be widely applied. The antibody that is conjugated can be easily adapted (based on the expressed cancer markers) and the type of nanocarrier can be changed (as long as surface amine groups are present). Here, the versatility of our coating strategy was demonstrated with two different antibodies, a CD44 and an EGFR antibody, both showing excellent selectivity towards CD44- and EGFR-overexpressing cells, respectively. This simple method can significantly contribute to the field of personalized cancer therapy, where the treatment should be customized according to the cancer markers present in the tumor. In this regard, a variety of antibodies can be easily "clicked-on" for efficient targeting purposes.

Supplementary Materials: The following are available online at https:/ / www.mdpi.com/article/10 .3390 / pharmaceutics13122153/s1: Figure S1. Emission and excitation spectra of drug and dye-loaded MSNPs. Figure S2. Absorbance for dual-labelled antibodies (IgG/DBCO/Atto565, EGFR/DBCO/ Atto565 and CD44/DBCO/Atto565), non-labelled antibodies (IgG, EGFR and CD44) and DBCO only. Figure S3. (a) AFM images of MSNPs, PEI-MSNP, $\alpha$ CD44-PEI-MSNPs and $\alpha$ CD44-PEI-MSNPs, (b) Graph of the average height measured with AFM (diameter). Figure S4. Confocal fluorescence microscopy images showing the influence of different MSNP coating in the uptake of nanoparticles in BJ1-tHERT and NIH 3T3 cells. Figure S5. Immunofluorescence (secondary goat-anti-rat IgGAF488) staining showing the expression of absence of the CD44 receptor in Bj-hTERT and NIH 3T3, respectively. Figure S6. Manders' Coefficient (MC) representing the fraction of overlap between the $\alpha$ CD44-PEI-MSNPs channel with the LysoTacker Deep Red channel. Figure S7. Internalization of $\alpha$ EGFR-PEI-MSNPs in wild type Hek293 (left panel) and Hek293 cells transiently transfected with a pcDBA3-EGFR-HaloTag®(middle and right panel). Table S1. $\alpha$ CD44-PEI-MSNP aggregation in different solutions: average OD600 values for $\alpha$ CD44-PEI-MSNPs dissolved in MilliQ water, FBS and DMEM with $10 \%$ FBS before and after $24 \mathrm{~h}$ of incubation at $37^{\circ} \mathrm{C}$.

Author Contributions: Conceptualization, I.V.Z., B.F. and S.R.; methodology, I.V.Z., M.B., P.C., O.D. and B.F.; formal analysis, I.V.Z. and O.D.; investigation, I.V.Z., M.B., P.C., O.D., B.F. and S.R.; writingoriginal draft preparation, I.V.Z., M.B. and S.R.; writing-review and editing, all authors; supervision, C.B., H.U.-i., J.H., B.F. and S.R.; funding acquisition, C.B., H.U.-i., J.H. and S.R. All authors have read and agreed to the published version of the manuscript. 
Funding: This work was supported by the Research Foundation-Flanders (FWO, projects G0A5817N, G0D4519N, 1529418N, G081916N and G094717N), by KU Leuven (C14/16/053, C14/18/061, and KA/20/026). This collaborative work was also financially supported by the JSPS "Core-to-Core Program A. Advanced Research Networks". I.V.Z. and B.F. acknowledge the support from FWO for their PhD and Postdoctoral fellowships, respectively (11F5419N and 12X1419N). P.C., J.H., H.U.-I., and S.R. acknowledge financial support from the SuperCol project that received funding from the European Union's Horizon 2020 research and innovation program under the Marie Skłodowska-Curie grant agreement No. 860914. J.H. further acknowledges the Flemish government through long-term structural funding from Methusalem (CASAS2, Meth/15/04). Figure S5. immunofluorescence (secondary goat-anti-rat IgG-AF488) staining showing the expres-sion of absence of the CD44 receptor in Bj-hTERT and NIH 3T3, respectively.

Institutional Review Board Statement: Not applicable.

Informed Consent Statement: Not applicable.

Data Availability Statement: The data presented in this study are available on request from the corresponding authors.

Acknowledgments: The authors acknowledge Roel Hammink (Radboud University, Nijmegen, NL) for the fruitful discussions concerning antibody functionalization and Hideaki Mizuno (KU Leuven) for providing us with the pcDNA3-EGFR-HaloTag ${ }^{\circledR}$ plasmid and cell lines. Figure 1 was created with Biorender.com (accessed date 1 May 2021).

Conflicts of Interest: There are no conflicts of interest regarding this research.

\section{References}

1. Sriraman, S.K.; Aryasomayajula, B.; Torchilin, V.P. Barriers to Drug Delivery in Solid Tumors. Tissue Barriers 2014, 2, e29528. [CrossRef] [PubMed]

2. Cho, H.-J.; Yoon, I.-S.; Yoon, H.Y.; Koo, H.; Jin, Y.-J.; Ko, S.-H.; Shim, J.S.; Kim, K.; Kwon, I.C.; Kim, D.D. Polyethylene GlycolConjugated Hyaluronic Acid-Ceramide Self-Assembled Nanoparticles for Targeted Delivery of Doxorubicin. Biomaterials 2012, 33, 1190-1200. [CrossRef] [PubMed]

3. Yang, L.; Shi, P.; Zhao, G.; Xu, J.; Peng, W.; Zhang, J.; Zhang, G.; Wang, X.; Dong, Z.; Chen, F.; et al. Targeting Cancer Stem Cell Pathways for Cancer Therapy. Signal Transduct. Target. Ther. 2020, 5, 1-35. [CrossRef] [PubMed]

4. Greish, K. Enhanced Permeability and Retention (EPR) Effect for Anticancer Nanomedicine Drug Targeting. Methods Mol. Biol. 2010, 624, 25-37. [CrossRef]

5. Zwicke, G.L.; Mansoori, G.A.; Jeffery, C.J. Utilizing the Folate Receptor for Active Targeting of Cancer Nanotherapeutics. Nano Rev. 2012, 3, 18496. [CrossRef]

6. Akhter, M.H.; Beg, S.; Tarique, M.; Malik, A.; Afaq, S.; Choudhry, H.; Hosawi, S. Receptor-Based Targeting of Engineered Nanocarrier against Solid Tumors: Recent Progress and Challenges Ahead. Biochim. Biophys. Acta Gen. Subj. 2020, $1865,129777$. [CrossRef]

7. Wang, A.Z. EPR or no EPR? The Billion-Dollar Question. Sci. Transl. Med. 2015, 7, ec112-ec294. [CrossRef]

8. Nel, A.; Ruoslahti, E.; Meng, H. New Insights into "Permeability" as in the Enhanced Permeability and Retention Effect of Cancer Nanotherapeutics. ACS Nano 2017, 11, 9567-9569. [CrossRef] [PubMed]

9. Dai, Q.; Wilhelm, S.; Ding, D.; Syed, A.M.; Sindhwani, S.; Zhang, Y.; Chen, Y.Y.; MacMillan, P.; Chan, W.C. Quantifying the Ligand-Coated Nanoparticle Delivery to Cancer Cells in Solid Tumors. ACS Nano 2018, 12, 8423-8435. [CrossRef] [PubMed]

10. Zhang, H.; Lee, M.-Y.; Hogg, M.G.; Dordick, J.S.; Sharfstein, S.T. Gene Delivery in Three-Dimensional Cell Cultures by Superparamagnetic Nanoparticles. ACS Nano 2010, 4, 4733-4743. [CrossRef]

11. Wilhelm, S.; Tavares, A.J.; Dai, Q.; Ohta, S.; Audet, J.; Dvorak, H.F.; Chan, W.C. Analysis of Nanoparticle Delivery to Tumours. Nat. Rev. Mater. 2016, 1, 16014. [CrossRef]

12. Ukidve, A.; Cu, K.; Kumbhojkar, N.; Lahann, J.; Mitragotri, S. Overcoming Biological Barriers to Improve Solid Tumor Immunotherapy. Drug Deliv. Transl. Res. 2021, 11, 2276-2301. [CrossRef] [PubMed]

13. Zhou, Y.; Chen, X.; Cao, J.; Gao, H. Overcoming the Biological Barriers in the Tumor Microenvironment for Improving Drug Delivery and Efficacy. J. Mater. Chem. B 2020, 8, 6765-6781. [CrossRef] [PubMed]

14. Van Zundert, I.; Fortuni, B.; Rocha, S. From 2D to 3D Cancer Cell Models-The Enigmas of Drug Delivery Research. Nanomaterials 2020, 10, 2236. [CrossRef]

15. Sherman, M.H.; Yu, R.T.; Engle, D.D.; Ding, N.; Atkins, A.R.; Tiriac, H.; Collisson, E.A.; Connor, F.; Van Dyke, T.; Kozlov, S.; et al. Vitamin D Receptor-Mediated Stromal Reprogramming Suppresses Pancreatitis and Enhances Pancreatic Cancer Therapy. Cell 2014, 159, 80-93. [CrossRef]

16. Bertrand, N.; Wu, J.; Xu, X.; Kamaly, N.; Farokhzad, O.C. Cancer Nanotechnology: The Impact of Passive and Active Targeting in the Era of Modern Cancer Biology. Adv. Drug Deliv. Rev. 2014, 66, 2-25. [CrossRef] [PubMed] 
17. Bhirde, A.A.; Patel, V.; Gavard, J.; Zhang, G.; Sousa, A.A.; Masedunskas, A.; Leapman, R.D.; Weigert, R.; Gutkind, J.S.; Rusling, J.F. Targeted Killing of Cancer Cells in vivo and in vitro with EGF-Directed Carbon Nanotube-based Drug Delivery. ACS Nano 2009, 3, 307-316. [CrossRef]

18. Gan, C.W.; Feng, S.-S. Transferrin-Conjugated Nanoparticles of Poly(Lactide)-D-Alpha-Tocopheryl Polyethylene Glycol Succinate Diblock Copolymer for Targeted Drug Delivery across the Blood-Brain Barrier. Biomaterials 2010, 31, 7748-7757. [CrossRef]

19. Gerber, D.E. Targeted Therapies: A New Generation of Cancer Treatments. Am. Fam. Physician 2008, 77, 311-319.

20. Gaspar, V.M.; Costa, E.C.; Queiroz, J.A.; Pichon, C.; Sousa, F.; Correia, I.J. Folate-Targeted Multifunctional Amino Acid-Chitosan Nanoparticles for Improved Cancer Therapy. Pharm. Res. 2015, 32, 562-577. [CrossRef]

21. Wang, X.; Li, J.; Wang, Y.; Koenig, L.; Gjyrezi, A.; Giannakakou, P.; Shin, E.H.; Tighiouart, M.; Chen, Z.; Nie, S.; et al. A Folate Receptor-Targeting Nanoparticle Minimizes Drug Resistance in a Human Cancer Model. ACS Nano 2011, 5, 6184-6194. [CrossRef]

22. Hsu, J.L.; Hung, M.-C. The Role of HER2, EGFR, and Other Receptor Tyrosine Kinases in Breast Cancer. Cancer Metastasis Rev. 2016, 35, 575-588. [CrossRef] [PubMed]

23. Lumachi, F.; Brunello, A.; Maruzzo, M.; Basso, U.; Basso, S.M.M. Treatment of Estrogen Receptor-Positive Breast Cancer. Curr. Med. Chem. 2013, 20, 596-604. [CrossRef] [PubMed]

24. Perou, C.M.; Sørlie, T.; Eisen, M.B.; van de Rijn, M.; Jeffrey, S.S.; Rees, C.A.; Pollack, J.R.; Ross, D.T.; Johnsen, H.; Akslen, L.A.; et al. Molecular Portraits of Human Breast Tumours. Nature 2000, 406, 747-752. [CrossRef]

25. Senter, P.D.; Sievers, E.L. The Discovery and Development of Brentuximab Vedotin for Use in Relapsed Hodgkin Lymphoma and Systemic Anaplastic Large Cell Lymphoma. Nat. Biotechnol. 2012, 30, 631-637. [CrossRef] [PubMed]

26. Amiri-Kordestani, L.; Blumenthal, G.M.; Xu, Q.C.; Zhang, L.; Tang, S.W.; Ha, L.; Weinberg, W.C.; Chi, B.; Candau-Chacon, R.; Hughes, P.; et al. FDA Approval: Ado-Trastuzumab Emtansine for the Treatment of Patients with HER2-Positive Metastatic Breast Cancer. Clin. Cancer Res. 2014, 20, 4436-4441. [CrossRef] [PubMed]

27. Wynne, J.; Wright, D.; Stock, W. Inotuzumab: From Preclinical Development to Success in B-cell Acute Lymphoblastic Leukemia. Blood Adv. 2019, 3, 96-104. [CrossRef]

28. Hafeez, U.; Parakh, S.; Gan, H.K.; Scott, A.M. Antibody-Drug Conjugates for Cancer Therapy. Molecules 2020, 25, 4764. [CrossRef] [PubMed]

29. Hammood, M.; Craig, A.W.; Leyton, J.V. Impact of Endocytosis Mechanisms for the Receptors Targeted by the Currently Approved Antibody-Drug Conjugates (ADCs)—A Necessity for Future ADC Research and Development. Pharmaceuticals 2021, 14, 674. [CrossRef] [PubMed]

30. Johnston, M.C.; Scott, C.J. Antibody Conjugated Nanoparticles as a Novel Form of Antibody Drug Conjugate Chemotherapy. Drug Discov. Today Technol. 2018, 30, 63-69. [CrossRef]

31. Juan, A.; Cimas, F.J.; Bravo, I.; Pandiella, A.; Ocaña, A.; Alonso-Moreno, C. An Overview of Antibody Conjugated Polymeric Nanoparticles for Breast Cancer Therapy. Pharmaceutics 2020, 12, 802. [CrossRef] [PubMed]

32. Yu, K.; Zhao, J.; Zhang, Z.; Gao, Y.; Zhou, Y.; Teng, L.; Li, Y. Enhanced Delivery of Paclitaxel Using Electrostatically-Conjugated Herceptin-Bearing PEI/PLGA Nanoparticles against HER-Positive Breast Cancer Cells. Int. J. Pharm. 2016, 497, 78-87. [CrossRef]

33. Mi, Y.; Huang, Y.; Deng, J. The Enhanced Delivery of Salinomycin to CD133+ Ovarian Cancer Stem Cells through CD133 Antibody Conjugation with Poly(Lactic-Co-Glycolic Acid)-Poly(Ethylene Glycol) Nanoparticles. Oncol. Lett. 2018, 15, 6611-6621. [CrossRef] [PubMed]

34. Varshosaz, J.; Davoudi, M.A.; Rasoul-Amini, S. Docetaxel-Loaded Nanostructured Lipid Carriers Functionalized with Trastuzumab (Herceptin) for HER2-Positive Breast Cancer Cells. J. Liposome Res. 2018, 28, 285-295. [CrossRef]

35. Chen, S.; Florinas, S.; Teitgen, A.; Xu, Z.-Q.; Gao, C.; Wu, H.; Kataoka, K.; Cabral, H.; Christie, R.J. Controlled Fab Installation onto Polymeric Micelle Nanoparticles for Tuned Bioactivity. Sci. Technol. Adv. Mater. 2017, 18, 666-680. [CrossRef]

36. Wartlick, H.; Michaelis, K.; Balthasar, S.; Strebhardt, K.; Kreuter, J.; Langer, K. Highly Specific HER2-Mediated Cellular Uptake of Antibody-Modified Nanoparticles in Tumour Cells. J. Drug Target. 2004, 12, 461-471. [CrossRef]

37. Goossens, J.; Sein, H.; Lu, S.; Radwanska, M.; Muyldermans, S.; Sterckx, Y.G.-J.; Magez, S. Functionalization of Gold Nanoparticles with Nanobodies through Physical Adsorption. Anal. Methods 2017, 9, 3430-3440. [CrossRef]

38. Choi, J.-S.; Jang, W.S.; Park, J.-S. Comparison of Adsorption and Conjugation of Herceptin on Poly(Lactic-Co-Glycolic Acid) Nanoparticles-Effect on Cell Internalization in Breast Cancer Cells. Mater. Sci. Eng. C Mater. Biol. Appl. 2018, 92, 496-507. [CrossRef]

39. Jain, A.; Cheng, K. The Principles and Applications of Avidin-Based Nanoparticles in Drug Delivery and Diagnosis. J. Control. Release 2017, 245, 27-40. [CrossRef]

40. Sperling, R.A.; Parak, W.J. Surface Modification, Functionalization and Bioconjugation of Colloidal Inorganic Nanoparticles. Philos. Trans. A Math. Phys. Eng. Sci. 2010, 368, 1333-1383. [CrossRef]

41. Kim, C.; Galloway, J.F.; Lee, K.H.; Searson, P.C. Universal Antibody Conjugation to Nanoparticles Using the Fc $\gamma$ Receptor I (Fc $\gamma$ RI): Quantitative Profiling Of Membrane Biomarkers. Bioconjug Chem. 2014, 25, 1893-1901. [CrossRef]

42. Kim, E.; Koo, H. Biomedical Applications of Copper-Free Click Chemistry: In vitro, in vivo, and ex vivo. Chem. Sci. 2019, 10, 7835-7851. [CrossRef]

43. Egorova, K.S.; Ananikov, V.P. Toxicity of Metal Compounds: Knowledge and Myths. Organometallics 2017, 36, 4071-4090. [CrossRef] 
44. Sigismund, S.; Avanzato, D.; Lanzetti, L. Emerging Functions of the EGFR in Cancer. Mol. Oncol. 2018, 12, 3-20. [CrossRef] [PubMed]

45. Naor, D.; Sionov, R.V.; Ish-Shalom, D. CD44: Structure, Function, and Association with the Malignant Process. Adv. Cancer Res. 1997, 71, 241-319. [CrossRef] [PubMed]

46. Slowing, I.I.; Trewyn, B.G.; Giri, S.; Lin, V.S.-Y. Mesoporous Silica Nanoparticles for Drug Delivery and Biosensing Applications. Adv. Funct. Mater. 2007, 17, 1225-1236. [CrossRef]

47. Wang, S. Ordered Mesoporous Materials for Drug Delivery. Microporous Mesoporous Mater. 2009, 117, 1-9. [CrossRef]

48. Garrido-Cano, I.; Candela-Noguera, V.; Herrera, G.; Cejalvo, J.M.; Lluch, A.; Marcos, M.D.; Sancenon, F.; Eroles, P.; MartínezMáñez, R. Biocompatibility and Internalization Assessment of Bare and Functionalised Mesoporous Silica Nanoparticles. Microporous Mesoporous Mater. 2021, 310, 110593. [CrossRef]

49. Fortuni, B.; Inose, T.; Ricci, M.; Fujita, Y.; Van Zundert, I.; Masuhara, A.; Fron, E.; Mizuno, H.; Latterini, L.; Rocha, S.; et al. Polymeric Engineering of Nanoparticles for Highly Efficient Multifunctional Drug Delivery Systems. Sci. Rep. 2019, 9, 2666. [CrossRef]

50. Thirukkumaran, O.M.; Kluba, M.; Hofkens, J.; Mizuno, H. Autophosphorylation of EGFR at Y954 Facilitated Homodimerization and Enhanced Downstream Signals. Biophys. J. 2020, 119, 2127-2137. [CrossRef]

51. Taemaitree, F.; Fortuni, B.; Koseki, Y.; Fron, E.; Rocha, S.; Hofkens, J.; Uji-i, H.; Inose, T.; Kasai, H. FRET-Based Intracellular Investigation of Nanoprodrugs toward Highly Efficient Anticancer Drug Delivery. Nanoscale 2020, 12, 16710-16715. [CrossRef]

52. Hammink, R.; Weiden, J.; Voerman, D.; Popelier, C.; Eggermont, L.J.; Schluck, M.; Figdor, C.G.; Verdoes, M. Semiflexible Immunobrushes Induce Enhanced T Cell Activation and Expansion. ACS Appl. Mater. Interfaces 2021, 13, 16007-16018. [CrossRef] [PubMed]

53. Wiener, J.; Kokotek, D.; Rosowski, S.; Lickert, H.; Meier, M. Preparation of Single- and Double-Oligonucleotide Antibody Conjugates and Their Application for Protein Analytics. Sci. Rep. 2020, 10, 1457. [CrossRef] [PubMed]

54. Shen, D.; Yang, J.; Li, X.; Zhou, L.; Zhang, R.; Li, W.; Chen, L.; Wang, R.; Zhang, F.; Zhao, D. Biphase Stratification Approach to Three-Dimensional Dendritic Biodegradable Mesoporous Silica Nanospheres. Nano Lett. 2014, 14, 923-932. [CrossRef] [PubMed]

55. Nečas, D.; Klapetek, P. Gwyddion: An Open-Source Software for SPM Data Analysis. Open Phys. 2012, 10, 181-188. [CrossRef]

56. Schindelin, J.; Arganda-Carreras, I.; Frise, E.; Kaynig, V.; Longair, M.; Pietzsch, T.; Preibisch, S.; Rueden, C.; Saalfeld, S.; Schmid, B.; et al. Fiji: An Open-Source Platform for Biological-Image Analysis. Nat. Methods 2012, 9, 676-682. [CrossRef] [PubMed]

57. Bolte, S.; Cordelières, F.P. A Guided Tour into Subcellular Colocalization Analysis in Light Microscopy. J. Microsc. 2006, 224, 213-232. [CrossRef]

58. Manders, E.M.M.; Verbeek, F.J.; Aten, J.A. Measurement of Co-Localization of Objects in Dual-Colour Confocal Images. J. Microsc. 1993, 169, 375-382. [CrossRef]

59. Goedhart, J. Plots of Differences-A Web App for the Quantitative Comparison of Unpaired Data. BioRxiv 2019, 578575. [CrossRef]

60. Penno, M.B.; August, J.T.; Baylin, S.B.; Mabry, M.; Linnoila, R.I.; Lee, V.S.; Croteau, D.; Yang, X.L.; Rosada, C. Expression of CD44 in Human Lung Tumors. Cancer Res. 1994, 54, 1381-1387.

61. Dalerba, P.; Dylla, S.J.; Park, I.-K.; Liu, R.; Wang, X.; Cho, R.W.; Hoey, T.; Gurney, A.; Huang, E.H.; Simeone, D.M.; et al. Phenotypic Characterization of Human Colorectal Cancer Stem Cells. Proc. Natl. Acad. Sci. USA 2007, 104, 10158-10163. [CrossRef]

62. Al-Hajj, M.; Wicha, M.S.; Benito-Hernandez, A.; Morrison, S.J.; Clarke, M.F. Prospective Identification of Tumorigenic Breast Cancer Cells. Proc. Natl. Acad. Sci. USA 2003, 100, 3983-3988. [CrossRef]

63. Arabi, L.; Badiee, A.; Mosaffa, F.; Jaafari, M.R. Targeting CD44 Expressing Cancer Cells with Anti-CD44 Monoclonal Antibody Improves Cellular Uptake and Antitumor Efficacy of Liposomal Doxorubicin. J. Control. Release 2015, 220, 275-286. [CrossRef]

64. Collins, A.T.; Berry, P.A.; Hyde, C.; Stower, M.J.; Maitland, N.J. Prospective Identification of Tumorigenic Prostate Cancer Stem Cells. Cancer Res. 2005, 65, 10946-10951. [CrossRef]

65. Ayob, A.Z.; Ramasamy, T.S. Cancer Stem Cells as Key Drivers of Tumour Progression. J. Biomed. Sci. 2018, 25, 20. [CrossRef] [PubMed]

66. Arpicco, S.; Lerda, C.; Dalla Pozza, E.; Costanzo, C.; Tsapis, N.; Stella, B.; Donadelli, M.; Dando, I.; Fattal, E.; Cattel, L.; et al. Hyaluronic Acid-Coated Liposomes for Active Targeting of Gemcitabine. Eur. J. Pharm. Biopharm. 2013, 85, 373-380. [CrossRef] [PubMed]

67. Chen, Z.; Li, Z.; Lin, Y.; Yin, M.; Ren, J.; Qu, X. Bioresponsive Hyaluronic Acid-Capped Mesoporous Silica Nanoparticles for Targeted Drug Delivery. Chemistry 2013, 19, 1778-1783. [CrossRef] [PubMed]

68. Wei, J.; Sun, J.; Liu, Y. Enhanced Targeting of Prostate Cancer-Initiating Cells by Salinomycin-Encapsulated Lipid-PLGA Nanoparticles Linked with CD44 Antibodies. Oncol. Lett. 2019, 17, 4024-4033. [CrossRef] [PubMed]

69. Wang, L.; Su, W.; Liu, Z.; Zhou, M.; Chen, S.; Chen, Y.; Lu, D.; Liu, Y.; Fan, Y.; Zheng, Y.; et al. CD44 Antibody-Targeted Liposomal Nanoparticles for Molecular Imaging and Therapy of Hepatocellular Carcinoma. Biomaterials 2012, 33, 5107-5114. [CrossRef]

70. Su, Z.; Liu, D.; Chen, L.; Zhang, J.; Ru, L.; Chen, Z.; Gao, Z.; Wang, X. CD44-Targeted Magnetic Nanoparticles Kill Head And Neck Squamous Cell Carcinoma Stem Cells In An Alternating Magnetic Field. Int. J. Nanomed. 2019, 14, 7549-7560. [CrossRef] [PubMed] 
71. Danielsson, Å.; Ljunglöf, A.; Lindblom, H. One-Step Purification of Monoclonal IgG Antibodies from Mouse Ascites: An Evaluation of Different Adsorption Techniques Using High Performance Liquid Chromatography. J. Immunol. Methods 1988, 115, 79-88. [CrossRef]

72. Zhang, L.; Hu, D.; Salmain, M.; Liedberg, B.; Boujday, S. Direct Quantification of Surface Coverage of Antibody in IgG-Gold Nanoparticles Conjugates. Talanta 2019, 204, 875-881. [CrossRef] [PubMed]

73. Gregory, J. Monitoring Particle Aggregation Processes. Adv. Colloid Interface Sci. 2009, 147-148, 109-123. [CrossRef] [PubMed]

74. Foster, K.A.; Oster, C.G.; Mayer, M.M.; Avery, M.L.; Audus, K.L. Characterization of the A549 Cell Line as a Type II Pulmonary Epithelial Cell Model for Drug Metabolism. Exp. Cell. Res. 1998, 243, 359-366. [CrossRef] [PubMed]

75. Aden, D.P.; Fogel, A.; Plotkin, S.; Damjanov, I.; Knowles, B.B. Controlled Synthesis of HBsAg in a Differentiated Human Liver Carcinoma-Derived Cell Line. Nature 1979, 282, 615-616. [CrossRef]

76. Arvizo, R.R.; Miranda, O.R.; Thompson, M.A.; Pabelick, C.M.; Bhattacharya, R.; Robertson, J.D.; Rotello, V.M.; Prakash, Y.S.; Mukherjee, P. Effect of Nanoparticle Surface Charge at the Plasma Membrane and Beyond. Nano Lett. 2010, 10, $2543-2548$. [CrossRef] [PubMed]

77. Xia, T.; Kovochich, M.; Liong, M.; Meng, H.; Kabehie, S.; George, S.; Zink, J.I.; Nel, A.E. Polyethyleneimine Coating Enhances the Cellular Uptake of Mesoporous Silica Nanoparticles and Allows Safe Delivery of siRNA and DNA Constructs. ACS Nano 2009, 3, 3273-3286. [CrossRef]

78. Shao, J.; Liang, R.; Ding, D.; Zheng, X.; Zhu, X.; Hu, S.; Wei, H.; Wei, B. A Smart Multifunctional Nanoparticle for Enhanced Near-Infrared Image-Guided Photothermal Therapy Against Gastric Cancer. IJN 2021, 16, 2897-2915. [CrossRef]

79. Somasunderam, A.; Thiviyanathan, V.; Tanaka, T.; Li, X.; Neerathilingam, M.; Lokesh, G.L.R.; Mann, A.; Peng, Y.; Ferrari, M.; Klostergaard, J.; et al. Combinatorial Selection of DNA Thioaptamers Targeted to the HA Binding Domain of Human CD44. Biochemistry 2010, 49, 9106-9112. [CrossRef] [PubMed]

80. Ouellette, M.M.; McDaniel, L.D.; Wright, W.E.; Shay, J.W.; Schultz, R.A. The Establishment of Telomerase-Immortalized Cell Lines Representing Human Chromosome Instability Syndromes. Hum. Mol. Genet. 2000, 9, 403-411. [CrossRef] [PubMed]

81. Okamoto, N.; Yasukawa, M.; Nguyen, C.; Kasim, V.; Maida, Y.; Possemato, R.; Shibata, T.; Ligon, K.L.; Fukami, K.; Hahn, W.C.; et al. Maintenance of Tumor Initiating Cells of Defined Genetic Composition by Nucleostemin. Proc. Natl. Acad. Sci. USA 2011, 108, 20388-20393. [CrossRef] [PubMed]

82. Andrian, T.; Riera, R.; Pujals, S.; Albertazzi, L. Nanoscopy for Endosomal Escape Quantification. Nanoscale Adv. 2021, 3, 10-23. [CrossRef]

83. Selby, L.I.; Cortez-Jugo, C.M.; Such, G.K.; Johnston, A.P.R. Nanoescapology: Progress toward Understanding the Endosomal Escape of Polymeric Nanoparticles. Wiley Interdiscip. Rev. Nanomed. Nanobiotechnol. 2017, 9, e1452. [CrossRef]

84. Degors, I.M.S.; Wang, C.; Rehman, Z.U.; Zuhorn, I.S. Carriers Break Barriers in Drug Delivery: Endocytosis and Endosomal Escape of Gene Delivery Vectors. Acc. Chem. Res. 2019, 52, 1750-1760. [CrossRef]

85. Tacar, O.; Sriamornsak, P.; Dass, C.R. Doxorubicin: An Update on Anticancer Molecular Action, Toxicity and Novel Drug Delivery Systems. J. Pharm. Pharmacol. 2013, 65, 157-170. [CrossRef]

86. Kralj, S.; Rojnik, M.; Kos, J.; Makovec, D. Targeting EGFR-Overexpressed A431 Cells with EGF-Labeled Silica-Coated Magnetic Nanoparticles. J. Nanopart. Res. 2013, 15, 1666. [CrossRef]

87. Patel, J.; Amrutiya, J.; Bhatt, P.; Javia, A.; Jain, M.; Misra, A. Targeted Delivery of Monoclonal Antibody Conjugated Docetaxel Loaded PLGA Nanoparticles into EGFR Overexpressed Lung Tumour Cells. J. Microencapsul. 2018, 35, 204-217. [CrossRef]

88. Kuroda, S.; Tam, J.; Roth, J.A.; Sokolov, K.; Ramesh, R. EGFR-Targeted Plasmonic Magnetic Nanoparticles Suppress Lung Tumor Growth by Abrogating G2/M Cell-Cycle Arrest and Inducing DNA Damage. IJN 2014, 9, 3825-3839. [CrossRef]

89. Acharya, S.; Dilnawaz, F.; Sahoo, S.K. Targeted Epidermal Growth Factor Receptor Nanoparticle Bioconjugates for Breast Cancer Therapy. Biomaterials 2009, 30, 5737-5750. [CrossRef]

90. Zhang, Y.; Li, X.; Xu, X.; Luo, W.-J. Construction of a High-EGFR Expression Cell Line and Its Biological Properties Comparing with A431 Cell. Afr. J. Biotechnol. 2010, 9, 4674-4680. [CrossRef]

91. Zhang, F.; Wang, S.; Yin, L.; Yang, Y.; Guan, Y.; Wang, W.; Xu, H.; Tao, N. Quantification of Epidermal Growth Factor Receptor Expression Level and Binding Kinetics on Cell Surfaces by Surface Plasmon Resonance Imaging. Anal. Chem. 2015, 87, 9960-9965. [CrossRef] [PubMed] 